\title{
Impactos y gestión de las epidemias de fiebres y de sarampión en un contexto de fuerte irregularidad climática: el caso de Barcelona (1793-1794)
}

Impacts and management of fever and measles epidemics in a context of severe climatic irregularity: the case of Barcelona (1793-1794)

Impacte i gestió de les epidèmies de febres i xarampió en un context de forta irregularitat climàtica: el cas de Barcelona (1793-1794)

Kevin Albert Pometti Benítez ${ }^{1}$

Mariano Barriendos ${ }^{2}$

\section{Resumen}

El presente trabajo muestra un episodio de fuerte irregularidad climática, manifestada en una secuencia de eventos de lluvia torrencial y sequía. Dentro de este episodio, se producen tensiones en la producción agrícola y dificultades para asegurar la calidad del recurso hídrico. La situación se complica por el conflicto bélico existente con Francia, y las consiguientes movilizaciones de recursos y tropas. El resultado de los diferentes factores adversos es un complejo balance sanitario con múltiples brotes epidémicos agravados por las enfermedades ya propias y una tensión en la disponibilidad de recursos materiales y humanos para atender la situación.

Palabras clave: Barcelona, epidemias, fiebres, gestión de impactos, irregularidad climática, oscilación Maldà, sarampión, siglo xvIII.

1. ORCID: 0000-0002-1116-9704. Aix Marseille Université, CNRS, TELEMME y Universidad de Alicante. Correo electrónico:kpometti@gmail.com.

2. ORCID: 0000-0001-9220-1245. Departament d'Història i Arqueología. Universitat de Barcelona. Correo-e: mbarriendos@ ub.edu.

Este trabajo ha sido realizado en el marco del laboratorio de excelencia LabexMed - Les sciences humaines et sociales au coeur de l'interdisciplinarité pour la Méditerranée, referencia 10-LABX-0090. Asimismo, este trabajo se ha beneficiado de una ayuda del Estado francés gestionada por la Agence nationale de la recherche, dentro del proyecto Investissements d'Avenir A*MIDEX, referencia n. ${ }^{\circ}$ ANR-11-IDEX-0001-02.

Recibido: IV/ 2021 / Evaluado VI/2021. Versión definitiva: VIII/2021. 


\begin{abstract}
This work presents an episode of strong climatic irregularity, which manifested in a sequence of torrential rainfall and drought events. Within this episode, there were tensions in agricultural production and difficulties in ensuring the quality of water resources. The situation was aggravated by the existing war conflict with France, and the consequent mobilizations of resources and troops. One result of these different adverse factors was a complex public health situation with multiple epidemic outbreaks aggravated by the diseases already inherent and difficulties with the availability of material and human resources to deal with the situation.
\end{abstract}

Keywords: 18th century, Barcelona, climatic irregularity, epidemics, fevers, impact management, Maldà Oscillation, measles.

\title{
Resum
}

El present treball mostra un episodi de forta irregularitat climàtica, manifestada en una seqüència d'esdeveniments de pluja torrencial i sequera. Dins d'aquest episodi es produeixen tensions en la producció agrícola i dificultat per assegurar la qualitat del recurs hídric. La situació es complica pel conflicte bèllic existent amb França, i les mobilitzacions de recursos i tropes. El resultat dels diferents factors adversos és un complex equilibri sanitari amb múltiples brots epidèmics agreujats per les malalties ja pròpies i una tensió en la disponibilitat de recursos materials i humans per atendre la situació.

Paraules Clau: Barcelona, epidèmies, febres, gestió d'impactes, irregularitat climàtica, oscillació Maldà, xarampió, segle XVIII.

\section{Introducción}

La investigación en historia ambiental tiene un desarrollo relativamente reciente pero una gran diversidad de líneas de trabajo. El contexto de calentamiento global inducido por la actividad antrópica que se percibe de forma evidente desde los últimos decenios del siglo xx favorece el impulso de esta especialidad. Las temáticas se orientan al estudio de la reconstrucción de procesos naturales a partir de fuentes historiográficas, documentación técnica y bases de datos, integrando en el análisis el papel de la sociedad, sus actores e intereses. Pero, actualmente, la historia ambiental está explorando la temática de los riesgos naturales con una aproximación general y abierta, valorando los elementos naturales y sociales que intervienen, así como la diversidad de procesos que interactúan entre ellos (entre otros, Desaive 1972, Shrewsbury 1975, Braudel 1993). La investigación va más allá y también focaliza el análisis en los impactos producidos en la sociedad según los diferen- 
tes contextos históricos, y los procedimientos de gestión de las situaciones de emergencia y las estrategias de respuesta y superación. No cabe duda de que la búsqueda de patrones de comportamiento en el pasado para situaciones de crisis ambiental es uno de los objetivos que orienta la disciplina, en especial por lo que hace referencia al análisis de circunstancias ambientales adversas que hubiesen alterado las condiciones de salubridad de distintos espacios y sus efectos sobre la salud pública (Rosen 2015: 24; GilGuirado et al., 2016; White, 2011). El contexto de cambio global y crisis climática, con todas las incertidumbres de futuro que comportan, justifica este tipo de investigación y la recuperación de patrones naturales y sociales (Brázdil et al. 2005: 365-366; Casty et al. 2007: 795; De Zulueta y Bruce-Chwatt 1980; Sallares 2005: 201) que reducen la incertidumbre y contribuyen en la toma de decisiones.

El presente trabajo se encuadra en esta especialidad con una aproximación a una problemática ambiental compleja, en la que inciden unos comportamientos climáticos muy irregulares con la proliferación de riesgos biológicos diversos (Smith et al. 2014: 717), que incluyen diferentes brotes epidémicos. La cobertura temporal se centra en solo dos años, pero que concentran anomalías significativas a nivel de salud pública. El ámbito espacial de estudio se limita a la costa central catalana debido a la dificultad que supone la recuperación de datos climáticos y sanitarios en alta resolución temporal. Se trata de un sector con un gran centro urbano, con fuerte incremento demográfico en la época estudiada, y unas intensas relaciones comerciales tanto hacia el interior por vía terrestre como por vía marítima a diferentes escalas. Las problemáticas ambientales también son diversas e importantes, debido a la irregularidad estructural del clima mediterráneo, que implica una fuerte tensión en la obtención de recursos hídricos, y la presencia frecuente de eventos meteorológicos extremos. La ocurrencia de impactos directos e inducidos, y las alteraciones experimentadas en los procesos naturales, pero también en los sociales, crean afectaciones complejas cuyo estudio en el pasado contribuye al conocimiento de interacciones que generan todavía incertidumbre en el presente y para el futuro próximo (Alten, Kampen y Fontenille 2007: 35-57).

De este modo, resulta posible conocer la incidencia de procesos alterados de origen natural, pero también los impactos y respuestas que suscitan en la sociedad humana, tanto a nivel institucional como en las diferentes corporaciones profesionales y grupos sociales, pudiendo valorar la eficacia de las respuestas, conflictos suscitados, e incluso la generación de nuevas situaciones de desequilibrio post-impacto. Dentro de este conjunto, parece especialmente indicado tratar períodos en los que la problemática ambiental incluye episodios epidémicos. La vinculación entre anomalías climáticas y episodios epizoóticos y epidémicos no es fácil, pero el contexto actual justifica proponer una situación retrospectiva para suscitar los paralelismos entre condiciones ambientales y los mecanismos sociales de respuesta ante afectaciones en la salud pública.

El trabajo pretende analizar el comportamiento natural y la respuesta social de las administraciones frente a un brote epidémico de fiebres en un contexto de fuerte irregularidad climática como fue la oscilación Maldà, que afectó buena parte de Europa entre los años 1760 y 1800 en su período álgido, aunque se extiende probablemente hasta 1820 (Trigo et al. 2008: 100). 
La epidemia de fiebres que tuvo lugar en Barcelona, entre 1793 y 1795, es remarcable por la notable escasez de fuentes y trabajos que se refieren a ella. De hecho, resulta una epidemia que parece ocultada quizá por los propios acontecimientos históricos del momento, la guerra de la Convención y de la que apenas quedan rastros que seguir para los historiadores. Tal es así, como destacó Juan Riera Palmero, que incluso los trabajos de Joaquín de Villalba se centran más en las noticias de la progresión de la fiebre amarilla en Filadelfia, que en la epidemia de calenturas y fiebres que asolaba los ejércitos durante la contienda a la que hemos hecho referencia (Riera 1992: 119).

Una epidemia, de la que no disponemos de información hasta la noticia que hallamos en el Diario de Barcelona, de 19 de enero de 1821, junto con las cartas anónimas del año 1794. Sin embargo, no es hasta 1821 cuando encontramos un balance del impacto de las fiebres entre las tropas españolas a través de Antonio de Almodóvar, médico consultor de los ejércitos, quien constataba la presencia de una epidemia que «en los años de 1793 y 1794, en cuya desgraciada época Cataluña padecía el tiphus [sic], habiendo envuelto en su contagio a más de veinte mil combatientes de nuestro ejército». ${ }^{3}$ Una falta de trabajos que también preocupó a la Real Academia Médico-Práctica de Barcelona, quien amplió el período para aceptar todos aquellos estudios centrados en la descripción de una epidemia ocurrida en España desde 1782, hasta noviembre de 1794. De hecho, dejaban constancia de su preocupación al «no haber venido ninguna [memoria], relativa a las epidemias que desolaron el año pasado nuestro ejército del Rosellón, y varios pueblos del principado». ${ }^{4}$

Debido a la alteración de las condiciones ambientales generadas por la inestabilidad del clima, y en ocasiones favorecidas de manera indirecta por las actividades humanas (manufacturas textiles y peleteras, el cultivo del cáñamo o del arroz, entre otras) favorecieron un contexto propicio para la expansión de las fiebres en la península ibérica, especialmente en la década de los años ochenta, cuando se expandieron desde Lleida (1783) hasta alcanzar Cataluña entera, Aragón, Andalucía, La Mancha, Castilla la Nueva y la cuenca mediterránea entre 1784 y 1785 (Pérez 1980: 336-342). Una problemática que persistió en los años noventa del siglo xviI y aun con posterioridad junto con la llegada de morbos importados como la fiebre amarilla en 1803, 1821 y 1871 (Rico-Avello 1953: 4) o el cólera de 1833, entre otros. Desde los trabajos de Vicente Pérez-Moreda (1980) han transcurrido numerosas investigaciones centradas en el análisis de la relación entre las condiciones del medio y las fiebres, así como de los impactos que generaron sobre la sociedad en las postrimerías del siglo xviI, con una especial atención al levante peninsular, al litoral valenciano y alicantino (Vilar 1966: 309-314; Peset y Peset 1972; Riera 1982, 1984, 1992; Alberola y Pradells 2012; Alberola y Box 2016; Alberola 1985, 1989, 2010a, 2010b, 2012, 2014, 2018, 2019; Alberola y Bernabé; Betrán 2006; Bueno 2014, 2017; García, 2017, 2018; Giménez Font 2008). Nos hallamos ante una problemática que ha dado lugar a numerosos trabajos, pero si bien no podemos hacer referencia a todos ellos, sirvan de ejemplo los realizados en la región del Ampurdán (Pujiula

3. AHCB, CDH15, Diario de Barcelona, núm. 19, viernes 19 de enero de 1821, p. 169.

4. ARAMC, Llibres d'acords, vol. 1., «Junta pública de la Real Academia de Medicina Práctica de Barcelona, celebrada en 23 de marzo de 1795, siendo su presidente el Excelentísimo Señor Duque de la Alcudia», s./f. 
2008: 63; Moreno Chacón 2007: 531; Fabregat i Galcerà 2006), o centrados en la Albufera valenciana, como muestra de la secularidad de una problemática persistente, la de las fiebres, que no se solventó hasta la aplicación de medidas sistemáticas tanto a nivel de profilaxis y tratamiento como en la erradicación de los mosquitos mediante DDT o en la desecación de los parajes más problemáticos, tras la puesta en funcionamiento del Proyecto Oficial de Erradicación del Paludismo en España (1959-1962) (Rodríguez et al. 2003: 26).

Además, cabe destacar los estudios realizados sobre la región murciana (Sáez y Marset 2000), así como recientes trabajos centrados en los efectos de las fiebres en la ciudad de Barcelona y epizootias, entre 1780 y 1821 y en su periferia (Codina 1971, 1994, 2001, 2002). Los estudios, en las áreas endémicas, han resultado una constante a lo largo de la historia. Sirvan de ejemplo los trabajos realizados por Andrés Piquer y Arrufat (1751) en el caso de Valencia o Francisco Pons (1790) sobre el Ampurdán o el trabajo de Josep Masdevall (1786) centrado en la epidemia de fiebres de 1783 a 1786 que tuvo lugar en Cataluña, entre otros.

En cuanto a la problemática en torno a la salubridad de Barcelona, cabe señalar que en los años que centran este trabajo los habitantes de la urbe oscilaban cerca de los cien mil. Cifra que no se recuperó, de nuevo, hasta 1826 (Vilar 1966: 65-70). Una ciudad que presenta el comportamiento clásico de los patrones demográficos comunes a la Europa moderna: mortalidad y natalidad altas con un predominio de los nacimientos, pero en la que las puntas de mortalidad produjeron un crecimiento vegetativo muy moderado (Grabuleda 2002: 60). Nos hallamos ante una ciudad con serios problemas estructurales, en especial, a raíz de la destrucción del barrio de La Ribera debido a la construcción de la Ciudadela. Lo que ha dado lugar a un proceso de sobrepoblación del barrio de Sant Pere i del Born, donde se concentraban la mayor parte de las manufacturas urbanas (Espuche 2009: 108). Encontramos una población hacinada, que vivirá en viviendas reducidas a una habitación con los elementos indispensables y con grandes déficits en materia de higiene, un punto que llamará la atención de los médicos en las últimas décadas del siglo xviII. ${ }^{5} \mathrm{~A}$ su vez, el progresivo incremento poblacional del barrio de El Raval ocasionará que los médicos de Sanidad deban ejercer una mayor supervisión sobre los focos potenciales de infección (las murallas y fortificaciones, las condiciones de las canalizaciones de agua de consumo y de alcantarillado; además de las acequias, los espacios para arrojar las basuras o depositar estiércol...), ${ }^{6}$ lo que dará lugar a sucesivas normativas de sanidad, frecuentemente incumplidas a lo largo del período y también a recurrentes conflictos vecinales en reclamación de un mayor respeto de las medidas de higiene, que en la mayoría de los casos finalizaban con una solución que no entorpeciese el desarrollo productivo de la actividad económica.

5. Arxiu de la Reial Academia de Medicina de Catalunya, «Papeles del Dr. D. Francisco Salvá», legajo XIV, n. ${ }^{\circ} 8$, «Borrador de una curiosa descripción de Barcelona de fines del siglo xviII, s./f.

6. Proponemos la consulta de Pometti (2019b: 259-265), donde se realiza un análisis más detallado de las principales problemáticas en punto a las condiciones del medio y a los principales problemas de salubridad de la ciudad. Asimismo, recomendamos la consulta de los trabajos de Gemma García i Fuertes (1990: 68-171) y, entre otros, de Eloy Martín Corrales (2015: 215-238). En relación con el funcionamiento de las instituciones sanitarias en Cataluña y, en Barcelona, recomendamos la consulta del trabajo de Alfons Zarzoso (2003) e Iris Figuerola (1982). 


\section{Contexto climático: Episodios hidrometeorológicos extremos durante la fase final de la oscilación Maldà}

\section{Explicación de los diferentes factores que pueden incidir en periodos de alta irregularidad climática}

La paleoclimatología centra el esfuerzo investigador en la reconstrucción fiable y consistente de los comportamientos del clima del pasado a partir de la combinación de diferentes fuentes de información no instrumentales (multi-proxy approach). La variabilidad climática se puede identificar y caracterizar, aunque según las épocas y regiones estudiadas, los progresos son todavía diversos, dispares y requieren investigación continuada en el futuro. Sin embargo, el aspecto que todavía requiere mucha investigación coordinada e interdisciplinar es el referente a la identificación de factores causales de esas condiciones climáticas y ambientales, y la magnitud o grado de incidencia de cada uno de ellos.

Los factores ya conocidos como causantes de irregularidad en la variabilidad climática ofrecen para el período de finales de siglo xviII una presencia coincidente (Barriendos y Llasat 2003). No se pueden ofrecer análisis diagnósticos sobre la repercusión climática y ambiental de esta acumulación de factores adversos, pero su presencia es altamente significativa. Por otro lado, la investigación está más avanzada en el estudio de los factores que inciden en la variable temperatura, mientras que la variable precipitación es mucho más compleja de evaluar en su comportamiento. Aunque precisamente en la región mediterránea la temperatura no es una variable tan limitante como la precipitación, que constituye la base de los recursos hídricos para las actividades básicas de la sociedad y que no siempre están en una disponibilidad óptima ni suficiente: agricultura, manufacturas, producción energética, consumo humano, evacuación de residuos urbanos, salubridad, etc.

El primer factor que se contempla es la actividad volcánica. La aparición de erupciones volcánicas de gran magnitud es un hecho que suele documentarse sin problema. Son relevantes por su alcance global y la complejidad de impactos que produce, aunque su incidencia directa es relativamente breve, de unos tres años, cinco a lo sumo. Para el período estudiado, el evento más destacado se produjo el 8 de junio de 1783 en el sistema Laki (Islandia), una fisura de 25 kilómetros con más de cien cráteres. La erupción tuvo una larga duración y afectó la calidad del aire en toda Europa occidental. A efectos climáticos, la repercusión más evidente fue un incremento de episodios de lluvia persistente y de inundaciones en las cuencas del litoral mediterráneo español hasta bien entrado el año 1784, de forma notablemente independiente al régimen estacional de las precipitaciones (Alberola et al. 2018).

El factor que quizá tiene una implicación más evidente en la variabilidad climática son las fluctuaciones en la constante solar, aunque es difícil todavía establecer correlaciones exactas con las anomalías o irregularidades en las variables climáticas, especialmente la precipitación (Barriendos y Llasat 2003).

Los últimos decenios del siglo xviI experimentaron comportamientos contrapuestos de la constante solar en un período de tiempo breve, lo que obviamente genera procesos atmosféricos y oceánicos inusuales. Entre 1775 y 1798 se producen dos ciclos de manchas 
solares (ISN, International Sunspot Number, 3 y 4) con una cantidad máxima de manchas inusualmente alta (264 y 235, respectivamente), cuando el valor medio está en 178,7 manchas. Ello supone un período en el que la constante solar está por encima de su valor medio, llegando más energía a las capas altas de la atmósfera terrestre. Ninguna reconstrucción anterior de ciclos solares había mostrado una actividad tan alta por lo menos en los últimos doscientos años previos. ${ }^{7}$

Después del comportamiento de máxima emisión de energía solar, se produce un fenómeno opuesto, con un fuerte descenso en el número de manchas solares, evento muy destacado que se conoce como Mínimo Dalton y que se extiende entre 1790 y 1820, abarcando los ciclos solares n. 5 y $6 .^{8}$ La situación, por lo que se refiere a la energía entrante en el sistema terrestre, experimenta en ese período unas irregularidades muy significativas, que sin duda deben alterar el clima a escala global y los procesos ambientales (Tejedor et al. 2017: 101).

Un tercer factor de incidencia climática que también aparece en el período de estudio son las alteraciones en los patrones de circulación termohalina, protagonizadas por las corrientes oceánicas. Muchos de estos patrones son poco conocidos y no se puede valorar su incidencia en la variabilidad climática. Pero por lo menos uno de ellos se conoce en detalle y se dispone de cronologías de escala temporal amplia: el patrón ENSO (El NiñoSouthern Oscillation), conocido habitualmente como el fenómeno de El Niño, consistente en una inversión de las corrientes oceánicas frías y cálidas que recorren la costa pacífica americana y se extienden hacia el Pacífico occidental. Su ámbito de impacto principal son los regímenes de lluvia en latitudes tropicales, causando lluvias torrenciales en la costa pacífica americana (Perú, Ecuador, Colombia), y prolongadas sequías en el Pacífico occidental afectando a Australia, Indonesia y otros países de la región. Se trata de un patrón relativamente frecuente y de comportamiento casi cíclico, pero de intensidades diferentes que se traducen en fuertes impactos en el medio natural y en las actividades humanas. Entre estos eventos más severos, en los últimos doscientos cincuenta años se han podido identificar y estudiar en detalle hasta nueve eventos. Los decenios más recientes, ya en un contexto de calentamiento global inducido por la actividad antrópica, acumulan cuatro de estos eventos. Pero resulta interesante destacar que el primer evento de gran magnitud que está documentado corresponde al período 1790-1793, asociado en consecuencia a las anomalías climáticas que se producen en torno al período estudiado (Grove 1998). Desgraciadamente, no se dispone de un conocimiento preciso de los efectos inducidos por un evento severo de ENSO más allá de las regiones adyacentes a donde se produce la reversión termohalina (Alpert et al. 2006: 156). Para Europa occidental, con los datos actuales se apunta una correlación con situaciones de sequía extraordinaria (Barriendos y Llasat 2003).

7. Ciclo solar 3: máximo ISN 264, mayo 1778. Duración 1775-1784. Ciclo solar 4: máximo ISN 235, febrero 1788. Duración 1784-1798. Fuente: SIDC (Solar Influences Data analysis Center). WDC-SILSO. Real Observatorio de Bélgica (http:// sidc.be/silso/home).

8. Ciclo solar 5: máximo ISN 82, febrero 1805. Ciclo solar 6: máximo ISN 81, mayo 1816. Fuente: SIDC (Solar Influences Data analysis Center). WDC-SILSO. Real Observatorio de Bélgica (http://sidc.be/silso/home). 
El último factor que interviene en la irregularidad climática del período estudiado es la propia variabilidad que genera la circulación general atmosférica. Por supuesto, su comportamiento es el resultado en buena medida de los factores antes detallados. Pero por ella misma, la dinámica atmosférica puede incorporar matices a lo que se considera una circulación general habitual, con el desplazamiento de masas de aire en sentido zonal. Por ejemplo, haciendo que un régimen de paso de borrascas o la estabilización de un anticiclón en una región se prolonguen más de lo habitual. El nivel de conocimiento en estos procesos que se producen en una escala de tiempo entre el fenómeno meteorológico (días) y la fluctuación climática (años) no es fácil.

El único recurso para poder identificar situaciones realmente adversas o infrecuentes es disponer de registros instrumentales de presión atmosférica (Jones et al. 1999: 347-364). Para el siglo xviII, a pesar de disponer ya de aparatos de medición (el barómetro de Torricelli se inventa en 1643), no se han conservado series de datos con densidad y homogeneidad suficiente para poder reconstruir la circulación atmosférica en detalle. A lo sumo, se pueden establecer índices de circulación atmosférica diaria y mensual para algunas regiones, con una fiabilidad y representatividad modestas. En este sentido, algunas reconstrucciones sobre la circulación atmosférica en Europa occidental sugieren que entre 1760 y 1800 se produjo una fuerte irregularidad en los patrones de circulación habituales. El paso de borrascas atlánticas en recorrido Oeste-Este se hace poco frecuente, y predominan las situaciones muy contrastadas, con largos períodos de predominio anticiclónico y masas de aire de procedencia sahariana, sucedidos por períodos con presencia de masas de aire inestables, borrascas, alimentadas con flujos de procedencia polar.

\section{Características básicas de la oscilación Maldà}

Los factores de incidencia climática descritos en el apartado anterior, coincidentes en los últimos decenios del siglo xviı, producen una anomalía claramente identificable en las variables climáticas básicas entre los años 1760 y 1800. Su afectación en la península Ibérica es evidente, aunque se manifiesta de formas diversas, y su momento de máxima severidad se localiza hacia 1786, precisamente cuando el barón de Maldà indicó en sus registros documentales la percepción de que el clima estaba manifestándose de forma muy irregular e inhabitual. ${ }^{9}$ Este período de fuerte irregularidad climática, en honor a la persona que lo percibió y describió directamente, se definió como oscilación Maldà.

En términos generales, los últimos cuatro decenios del siglo xviI se caracterizan en la costa mediterránea española por un notable incremento en la frecuencia de eventos hidrometeorológicos extremos. Se perciben también anomalías térmicas, con importantes

9. «Lo dels trons ha vingut molt de nou per cosa extrahordinaria, pues que no acostuman a comensar les tronades que a mediats de Abril fins al Octubre. Es prova de haver fet mutació los Climas, y variat se lo temps per lo que mira a las estacions alguns anys ha», Archivo Histórico Municipal de Barcelona, Ms. A-202, Baró de Maldà, Calaix de Sastre, p. 79, 20 de marzo de 1786. 
olas de frío y nevadas extraordinarias (Barriendos 2000: 177). Pero lo más relevante es la sucesión acelerada y prácticamente simultánea de sequías muy severas con episodios de lluvias torrenciales que ocasionan importantes episodios de inundación. Esta simultaneidad se explica por el régimen de circulación atmosférica que favorece las situaciones antagónicas en secuencia rápida entre grandes anticiclones con embolsamiento de aire cálido y estable, con grandes borrascas con embolsamiento de aire frío e inestable que ocasiona fuertes precipitaciones. La sucesión constante y rápida de sequías e inundaciones no permite una disponibilidad razonable del recurso hídrico, con los consiguientes impactos en las actividades productivas de la zona afectada.

Para confirmar la singularidad de esta oscilación climática, se pueden comparar los resultados de trabajos que identifican los eventos de mayor severidad en la cuenca mediterránea española, referidos a episodios de sequía e inundación a escala plurisecular, empleando una cantidad y diversidad considerables de información. Un trabajo reciente sobre sequías (Tejedor et al. 2019: 1656) muestra los siguientes episodios muy severos desde el siglo xvi en la cuenca del Ebro y costa catalana: los años 1737, 1753, 1775, 1798 y 1817. Otro trabajo del mismo año identifica los períodos de mayor frecuencia de inundaciones catastróficas en la vertiente mediterránea española: 1324-1328, 1580-1620, 1774-1793, 1843-1877. Los resultados de ambos trabajos muestran una coincidencia de episodios muy severos y de carácter opuesto en el período 1774-1798. Se puede afirmar, por otro lado, que un comportamiento de este tipo no se observa en ningún otro período de las series temporales disponibles, obtenidas a partir de reconstrucciones basadas en fuentes documentales primarias (Barriendos 2007: 47). Su excepcionalidad puede explicar incidencias en la producción agraria, en la disponibilidad de los recursos hídricos y afectaciones en la economía y vida cotidiana de la población. Además, no es descartable que se produjeran alteraciones en los ecosistemas naturales que propiciaran impactos inducidos, como plagas y epidemias.

\section{Variabilidad climática, enfermedades y respuesta sanitaria y social: el caso de Barcelona (1791-1794)}

\section{Variabilidad climática y mortalidad. Aproximación al análisis de ambas variables en el contexto epidémico}

La preparación de un contexto climático en el que desarrollar un análisis de situaciones epidémicas es un ejercicio poco habitual, y aún menos en un período histórico para el que los datos disponibles no son todo lo completos que sería deseable. Además de la dificultad por conseguir información cuantitativa suficientemente densa y fiable, se produce también una importante falta de homogeneidad cuando se estudian sectores urbanos ya a finales de la Edad Moderna. El caso de Barcelona no es ajeno a estas circunstancias. Las poblaciones que emprenden a finales de siglo xviI un proceso de consolidación de la actividad comercial e industrial, que les crea suficientes capacidades de aprovisionamiento y recursos financieros e incluso logísticos para poder relativizar el impacto que pueden sufrir sus áreas agrarias in- 
mediatas frente a circunstancias hidrometeorológicas adversas. Por otro lado, la información sobre afectaciones meteorológicas (granizadas, lluvias, sequías, etc.) se obtiene en su gran mayoría por los registros de rogativas pro pluvia o pro serenitate, para obtener lluvia o el cese de las lluvias cuando resultan perjudiciales. Este mecanismo litúrgico se basa en unas sólidas convicciones religiosas que probablemente en aquella época ya no lo son tanto en ámbitos urbanos. Pocos años después, en 1812, un testimonio contemporáneo teme ya las burlas de la población si las rogativas no surten efecto «hubieran sin duda aguzado sus satíricas y mordaces lenguas aquellos incrédulos, materialistas, y toda la chusma de irreligionarios de que abunda esta Capital y que se burlan de la Protección de los Santos». ${ }^{10}$

De todos modos, las informaciones sobre situaciones adversas a resolución mensual para el período estudiado (tabla 1) permiten percibir una alta irregularidad en las primaveras entre 1787 y 1794 , con presencias alternas de sequías graves y episodios de precipitación con inundaciones pluviales y fluviales.

\section{Tabla 1}

\section{Cronología mensual de las situaciones hidrometeorológicas adversas en Barcelona, 1785-1795}

\begin{tabular}{|c|c|c|c|c|c|c|c|c|c|c|c|c|}
\hline AÑO & Ene. & Feb. & Mar. & Abr. & May. & Jun. & Jul. & Ago. & Sep. & Oct. & Nov. & Dic. \\
\hline 1785 & 0 & 0 & 1 & 0 & 0 & 0 & 0 & 0 & 0 & 0 & 0 & 0 \\
\hline 1786 & 0 & 0 & 0 & 0 & 0 & 0 & 0 & 0 & 0 & 0 & 0 & 0 \\
\hline 1787 & 3 & 0 & 0 & 0 & 0 & 0 & 0 & 0 & 2 & 1 & 0 & -2 \\
\hline 1788 & -2 & -1 & 0 & 0 & -1 & 0 & 0 & 0 & 2 & 1 & 0 & 0 \\
\hline 1789 & 0 & -1 & -2 & 0 & 0 & 0 & 0 & 0 & 0 & 0 & 0 & 0 \\
\hline \multirow[t]{2}{*}{1790} & \multirow[t]{2}{*}{2} & \multirow[t]{2}{*}{0} & -1 & \multirow[t]{2}{*}{0} & \multirow[t]{2}{*}{1} & \multirow[t]{2}{*}{0} & \multirow[t]{2}{*}{0} & \multirow[t]{2}{*}{0} & \multirow[t]{2}{*}{0} & \multirow[t]{2}{*}{0} & \multirow[t]{2}{*}{0} & \multirow[t]{2}{*}{0} \\
\hline & & & 2 & & & & & & & & & \\
\hline 1791 & 0 & 0 & -1 & -2 & 1 & 0 & 0 & 0 & 0 & 0 & 0 & 0 \\
\hline 1792 & 0 & 0 & 0 & 0 & 0 & 0 & 2 & 0 & 0 & 0 & 0 & 0 \\
\hline 1793 & -1 & 2 & 0 & 0 & 0 & 0 & 0 & 0 & 0 & 0 & 0 & 0 \\
\hline 1794 & 0 & 0 & 0 & 3 & 0 & 0 & 0 & 0 & 0 & 0 & 0 & 0 \\
\hline 1795 & 0 & 0 & 0 & 0 & 0 & 0 & 0 & 0 & 0 & 0 & 0 & 0 \\
\hline
\end{tabular}

Clave:

+3 (Azul oscuro): Inundación catastrófica.

+2 (Azul medio): Inundación extraordinaria.

+1 (Azul claro): Rogativas pro serenitate o inundación pluvial.

0 (Blanco): Situación de normalidad. Ausencia de situaciones adversas.

-1 (Amarillo): Rogativas pro pluvia nivel 1.

-2 (Rojo): Rogativas pro pluvia niveles 2 y 3.

-3 (Marrón): Rogativas pro pluvia niveles 4 y 5.

Fuente: elaboración propia a partir de los índices desarrollados para el proyecto de la Unión Europea IP-MILLENNIUM (Camuffo et al. 2010; Dominguez-Castro et al. 2012).

10. Biblioteca de la Universidad de Barcelona, Fondo de Manuscritos, Ms. 1802, R. Ferrer, «Barcelona Cautiva», vol. 1, 9 de abril de 1812 . 


\section{Gráfico 1}

Precipitación total anual estandarizada. Barcelona, 1787-1797

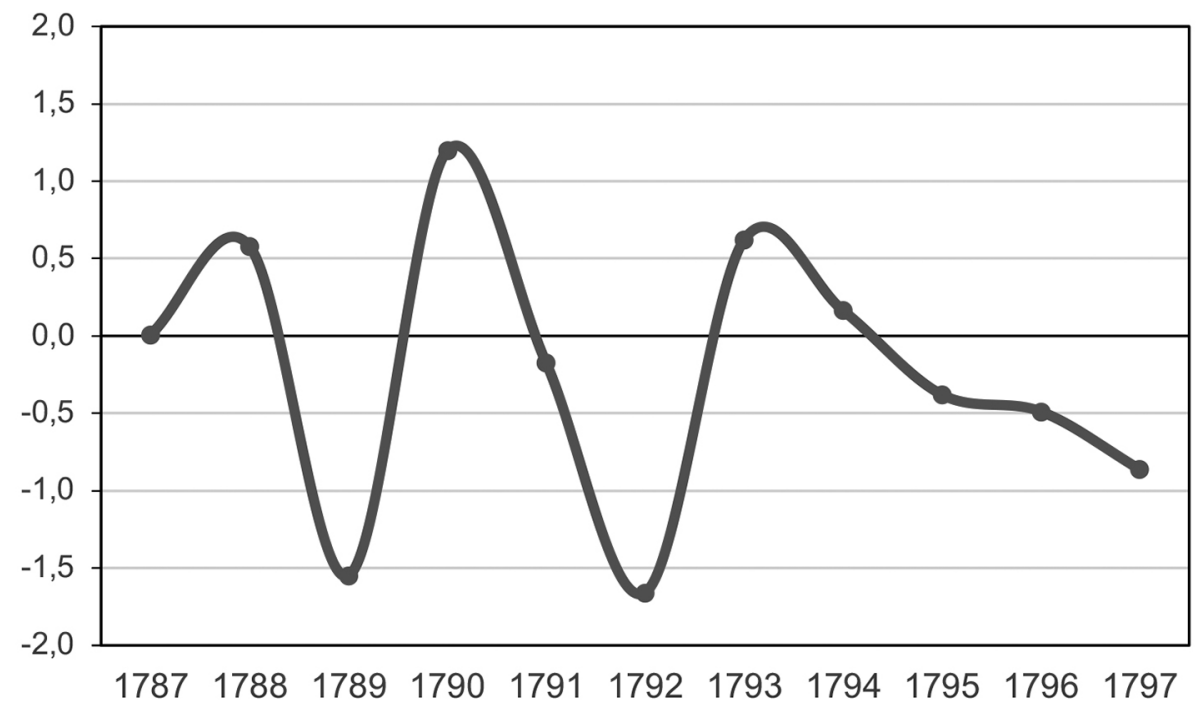

Período de referencia 1786-2020 (Promedio: 567,1 mm. Desviación estándar: 165,8 mm.).

Fuente: elaboración propia a partir de datos recopilados en: Archivo de la Real Academia de Medicina de Catalunya (ARAMC), Francisco Salvá, «Tablas Meteorológicas», 1780-1824, 4 vols.

La percepción climática del período quizá sería poco remarcable de no contar con datos instrumentales. Afortunadamente, la Real Academia de Medicina de Barcelona tuvo entre sus actividades científicas relevantes la observación meteorológica, lo que ha permitido disponer de registros instrumentales cuantitativos desde enero de 1780 gracias a la labor del Dr. Francisco Salvá Campillo. Sus registros, y los de los médicos que le sucedieron en esta actividad hasta el inicio de los registros estatales en el ámbito de la Universidad de Barcelona, son de una calidad que ha permitido la reconstrucción de la serie mensual de precipitación más prolongada de España, desde 1786 hasta la actualidad (Prohom et al. 2015).

Las precipitaciones totales anuales que están disponibles para el período 1787-1797 muestran un comportamiento muy irregular y de singulares características (gráfico 1). La serie estandarizada con el período de referencia más completo disponible (1786-2020) para la ciudad de Barcelona ofrece unas oscilaciones muy acusadas desde 1788 hasta 1793, de modo que casi cada año los valores de precipitación pasan de ser muy escasos (valores de $-1,5$ desviaciones estándares) a ser muy abundantes (valores entre $+0,5$ y $+1,0$ desviaciones estándares). El año 1794 puede considerarse de pluviometría normal pero los tres años siguientes (1795-1797) inician una tendencia muy acusada hacia una sequía climática severa. El momento álgido de irregularidad se produce entre los años 1788 (663,2 mm), 


\section{Gráfico 2 \\ Crecimiento vegetativo en Barcelona (1787-1796)}

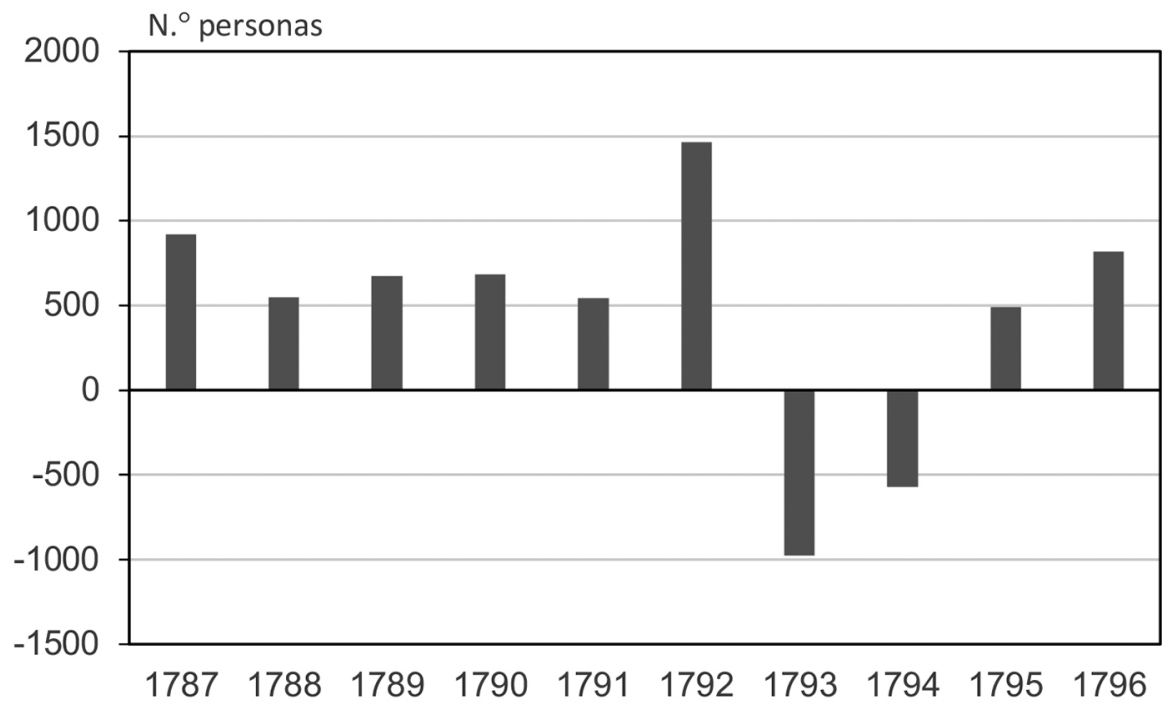

Fuente: elaboración propia a partir de los datos obtenidos en: ARAMC, Dr. Francisco Salvá Campillo, Legajo XII, n. ${ }^{\circ}$, Documento 8. «Tabla necrológica formada desde el año 1787 al 1796 inclusive».

1789 (310,2 mm), 1790 (765,8 mm), 1791 (538,0 mm) y 1792 (292,1 mm). Teniendo en cuenta que el valor medio de precipitación en Barcelona (1786-2020) es de 567,1 mm, solo el año 1791 se acerca a la normalidad entre años anómalamente lluviosos o secos. Bajo estas condiciones tan contrapuestas, la agricultura y el recurso hídrico tuvieron serias dificultades para poder cubrir las necesidades básicas de la población de la zona, tanto en cantidad como en calidad (Pometti 2019a: 720; Burgueño 2016: 125).

El estudio general de la evolución de la población de Barcelona confirma que se produjo algún tipo de impacto significativo que revertió la tendencia positiva del crecimiento vegetativo que mostraba la población (Pometti 2019a: 338-350). Según un estudio del Dr. Salvá (figura 2), el balance entre natalidad y mortalidad había resultado positivo entre 1787 y 1792 , mientras se estaba produciendo el momento álgido de la irregularidad pluviométrica (figura 1). De hecho, el año más seco del período coincide con el de mayor crecimiento vegetativo de la población, con un balance positivo absoluto de casi mil quinientos habitantes. Pero sin duda algún proceso acumulativo o de efecto diferido se produjo en Barcelona, ya que los dos años siguientes resultan con crecimiento vegetativo negativo: En 1793 se pierden casi mil habitantes y el año 1794 poco más de quinientos en cifras absolutas (figura 2). 


\section{Percepción y efectos de la inestabilidad climática entre 1791 y 1794: el testimonio de los coetáneos}

El contexto ambiental que precede a las epidemias de 1793-1794 estuvo enmarcado por un período de sequía extrema, en 1792, a la que sucedió una fase de alternancia entre la seca persistente y las precipitaciones de alta intensidad horaria. Un marco climático que comportó pérdidas notorias en las cosechas repercutiendo sobre las condiciones de alimentación de la población barcelonesa (Vilar 1966: 443-444; Anés 1974: 496).

La percepción de los primeros efectos de la sequía los ubicamos el 5 de abril de 1791 en los acuerdos municipales, cuando reunido el consistorio municipal se trató sobre la rogativa pro pluvia que había iniciado el Cabildo Eclesiástico:

En atención de que estándose haciendo algunos días ha, según aviso verbal, que por parte del Muy Ilustre Cabildo Eclesiástico de esta ciudad se dio al Sr. Decano del Ayuntamiento la rogativa de colecta en la misa para conseguir la divina misericordia el beneficio de la lluvia; no habiéndose esta logrado, ha pedido en vos el Sr. Síndico Procurador General que se sirva el Ayuntamiento resolver lo correspondiente a efecto de que se haga aquella otra cualidad de rogativa en estos casos sea costumbre. ${ }^{11}$

Los prohombres del gremio de labradores de la ciudad debido a la escasez de agua y al temor por perder la cosecha insistieron a la municipalidad, el 12 de abril de 1791, para que se realizasen rogativas pro pluvia en las que se sacasen las reliquias de Santa Madrona, para implorar la lluvia que conduciría al alivio de los campos pues no había duda de que de no llegar las ansiadas aguas «se perderá la mayor parte de la cosecha». ${ }^{12}$ En un contexto de serias limitaciones a nivel de desarrollo de las infraestructuras hídricas, del que es un buen ejemplo la situación que encontramos el 4 de mayo de 1792. Pues, es allí donde el ayuntamiento se hallaba lastrado por la incapacidad de ampliar la capacidad del suministro hídrico debido a los elevados costes que suponía mantener las redes de canalizaciones de aguas de consumo provenientes de las minas próximas a la ciudad. ${ }^{13}$

La escasez de agua y las limitaciones económicas del consistorio barcelonés condujeron a ceder al proyecto presentado por un particular, Ignacio de Fuxá, quien se ofrecía junto con sus socios a contribuir a las reparaciones necesarias de las minas de Moncada y de sus conductos para aumentar el caudal de las aguas que de allí se extraían a cambio de «poder usar para el servicio de sus casas alguna pluma, o plumas de agua que tuviese a bien concederles». ${ }^{14}$ La aceptación del ayuntamiento se tradujo en el empleo del agua para uso privado como una moneda de pago a cambio de las necesarias tareas de ampliación, limpieza y mantenimiento de las canalizaciones, en especial, en épocas de sequía extrema.

11. Arxiu Històric de la Ciutat de Barcelona, Fons Consell de la Ciutat i Ajuntament Modern, Acords, 1791, 1D. I-74, f. $93 \mathrm{r}$.

12. AHCB, Fons Consell de la Ciutat i Ajuntament Modern, Acords, 1791, 1D. I-74, f. 101 r.

13. AHCB, Fons Consell de la Ciutat i Ajuntament Modern, Acords, 1792, 1D. I-75, f. 92 r. y 93 r.

14. Idem. 
La sequía también produjo notorios problemas en torno a los abastos de trigos, con precios especialmente elevados en esos años entre 1793 y 1794 (Anés 1974: 496). Incluso antes, pues en 1792 los prohombres del Gremio de Horneros de Barcelona comunicaron de oficio al ayuntamiento, reunido en Real Acuerdo, que se escribiese al conde de Santa Coloma o a don Juan Ignacio de Güell, pues ambos se hallaban en la Corte, para pedirles que «se sirvan recordar la representación que el Ayuntamiento tiene pendiente solicitando el préstamo de ciento cuarenta mil libras para la compra de granos para el abasto del pan». ${ }^{15}$

No obstante, la escasez de trigo se hizo cada vez más crítica, hasta que el 27 de julio de ese año, la Junta de la Administración del abasto del pan hizo presente al ayuntamiento el deplorable estado económico en el que se hallaban y que había ocasionado que "por falta de los cuales [los caudales] no ha podido adherir a proposiciones de plazos para pago de trigos, que se le han hecho y con dificultad puede cumplir los de los que tiene ajustados». ${ }^{16}$ De hecho, la solicitud del préstamo de los recursos económicos necesarios para realizar la compra de granos se dirigió al conde de Santa Coloma, ya que como remarcaban los miembros de la Junta que al ser tan reducidos los medios no podían «atinar a otro que no sea o con pérdida de la administración o con próxima contingencia de haber de aumentar el precio del pan, el que tal vez podría conservarse si hubiese tenido dinero». ${ }^{17}$ La posibilidad de aumentar el precio del pan, considerado un producto de primera necesidad para el sustento de la población, sería una medida totalmente impopular y con nefastas consecuencias a nivel social, pues no podemos olvidar los estragos ocasionados por la revuelta que tuvo lugar entre el 28 de febrero y el 3 de marzo de 1789 a raíz de las crisis de subsistencia producidas por continuas cosechas deficitarias ocasionadas por una situación ambiental totalmente inestable a nivel europeo (Castells 1970: 68-74).

En consecuencia, para evitar una situación similar, se cedió a la entrega de las «diez y ocho mil trescientas veinte y nueve libras, siete sueldos y tres dineros que el Ayuntamiento tiene procedentes de los caudales de la Junta Benéfica». ${ }^{18}$ Sin embargo, la continua sequía y la persistente escasez de granos condujo a que el consistorio barcelonés proclamase, el 15 de abril de 1793, un bando en el que dejaban constancia de los impedimentos con los que se habían topado en el momento de acometer la importación del ansiado trigo. Esta vez no eran los problemas económicos sino los geopolíticos, como consecuencia de los efectos de la guerra de la Convención sobre el funcionamiento de las rutas comerciales, los que habían conducido a la municipalidad a tener que disminuir sustancialmente la calidad de la composición del pan para garantizar el abasto de un sucedáneo apto para el consumo de la población. Es así como habían tomado la decisión de conformar una nueva clase de pan que, en teoría, y de forma provisional, debía «no presentar al público un pan moreno de inferior calidad y menos grato a la vista a un pre-

15. AHCB, Fons Consell de la Ciutat i Ajuntament Modern, Acords, 1792, 1D. I-75, f. $112 \mathrm{v}$.

16. AHCB, Fons Consell de la Ciutat i Ajuntament Modern, Acords, 1792, 1D. I-75, f. 113 v. - 114 v.

17. Idem.

18. AHCB, Fons Consell de la Ciutat i Ajuntament Modern, Acords, 1792, 1D. I-75, f. 113 v. 
cio (por el exorbitante del de los trigos) igual al que sale el pan que se pone de venta». ${ }^{19}$ Para esto, establecieron:

Variar el método del abasto, reduciendo las tres clases de pan blanco, mediano y moreno a una sola con mezcla en cortas porciones de maíz, habones y cebada, granos de que (sic) se usan otros pueblos, y que a dictamen de los médicos de sanidad son saludables y no dañosos a la salud. ${ }^{20}$

Otro de los objetivos de la municipalidad ante la persistente carestía de los granos se centró en evitar la especulación. Para ello, establecieron los precios mediante los que se debía vender la única clase de pan que se comercializaría «al precio de trece dineros la libra, que a esta razón será el de seis libras a seis sueldos y seis dineros; el de tres libras a tres sueldos y tres dineros; el de libra y media a un sueldo y ocho dineros; el de libra a un sueldo y un dinero; y el de seis onzas a siete dineros». ${ }^{21}$ Además, se establecía que no se pudiese comercializar otra variedad de pan, bajo pena de veinticinco libras y el decomiso de la mercancía. ${ }^{22}$

El pan blanco, el de mayor calidad, se reservó de forma exclusiva para los enfermos y convalecientes y, además, a un precio comedido para facilitar su adquisición por los más desfavorecidos, a razón de «dos sueldos la libra en los barrios de Santa María, Plaza nueva, y calle del Hospital» siempre que se presentase la «certificación de médico visada por uno de los señores que el Ayuntamiento ha comisionado al referido efecto». ${ }^{23}$

A pesar de las disposiciones dadas por la municipalidad para paliar la escasez y para garantizar el sustento de la población más necesitada, el 16 de abril de 1793, los administradores del Hospital General de la Santa Creu se dirigieron al ayuntamiento a fin de que propusieran una solución ante la imperiosa falta de sustento alimenticio de los enfermos. Pues, afirmaban que únicamente tenían trigos «para continuar hasta el viernes las raciones de pan ${ }^{24}$ y remarcaban que no habían podido acceder a la compra de los pocos trigos que habían llegado a la ciudad por «estar tratando de ella con el Ayuntamiento» ${ }^{25}$ el comité de la Junta de Administración del Pan.

Por este motivo, la municipalidad acordó que se suministrasen al Hospital de la Santa Creu «200 cuarteras de trigo en inteligencia de que servirán precisamente para los enfermos», ${ }^{26}$ adelantando, para sufragar la falta de alimento de los convalecientes, las «100 cuarteras de trigo del que tenga el Ayuntamiento para el abasto del público, satisfaciéndolo aquel a coste y costas». ${ }^{27}$

19. AHCB, Fons Consell de la Ciutat i Ajuntament Modern, Acords, 1793, 1D. I-76, f. 81 v.- 82 r.

20. Idem.

21. Idem.

22. Para esto se remitieron al artículo 6 del Edicto de 26 de diciembre de 1789.

23. Idem.

24. AHCB, Fons Consell de la Ciutat i Ajuntament Modern, Acords 1793, 1D. I-76, f. 84 r.

25. Idem.

26. Idem.

27. Idem. 
Si algo caracteriza el contexto ambiental que enmarca las epidemias de fiebres de 1793 a 1794, es la inestabilidad. En este sentido, Francisco Salvá y Campillo, menciona en sus tablas meteorológicas que el invierno de 1793 fue de «los más fríos que suelen verse en esta ciudad $»^{28}$ y al que sucedieron «granizadas, rayos, truenos, y relámpagos, lo que tampoco suele observarse hasta el marzo». ${ }^{29}$ Un invierno frío y lluvioso, en los primeros meses de 1793, al que siguió una primavera templada que constituía la antesala de la ola de calor y de la sequía que caracterizaron el verano de ese año. Un episodio extremadamente caluroso que fue sucedido por las lluvias de noviembre de 1793 y por un otoño especialmente cálido. Un marco ambiental que adelantó de forma prematura la cosecha de granos, y que pudo contribuir a la proliferación de áreas inundadas en el interior de la urbe y en su periferia.

Es así como las avenidas de las aguas, a raíz de las intensas precipitaciones, que tuvieron lugar el 26 de noviembre de 1793 se tradujeron en la destrucción de la Acequia Condal, en las inmediaciones de Moncada «por lo cual quedan sin uso todos los molinos que han de correr con el agua de ella, y la Junta sin provisión de harinas sino para 4 o 5 días». ${ }^{30}$ Es decir, que además de los perjuicios sobre las infraestructuras se añadía la imposibilidad de moler los de por sí escasos granos en un contexto de persistente carestía. En consecuencia, el consistorio barcelonés restó a la espera de conocer los efectos producidos por los aguaceros en el Llobregat a la vez que pasaba un oficio al intendente para solicitar la pronta recomposición de los daños. Pues albergaban la esperanza de que, en el caso de haber permanecido las infraestructuras intactas, sería posible mantener activa la molienda y la consecuente producción de harinas en vistas a sufragar la escasez.

El de 1794 sería otro año caracterizado por la variabilidad del clima, perceptible ya en sus primeros meses, especialmente, a raíz de la calidez de su estación invernal, la cual no pasó desapercibida por Francisco Salvá, pues constató que el invierno de 1794 «fue poco frío, con especialidad en los meses de febrero y marzo, y en ninguno de los dos, ni tampoco en el de enero se vieron bajar [sic] el termómetro lo que otros años». ${ }^{31}$ Nos hallamos ante un período en el que a la calidez de los meses de invierno se añaden las consecuencias de la sequía en los meses de primavera, y las precipitaciones cuyos efectos, en su conjunto, conllevaron la pérdida de las cosechas, pues:

Duró la sequedad en el principio de la primavera, o en el mes de abril; pero en el de mayo y junio llovió más de lo que necesitábamos, y las lluvias perjudicaron bastante a los sembrados, y a los árboles frutales, que estaban en flor [...] la cosecha de granos cereales fue escasa aquí, y en todo el Principado, igualmente que la de las frutas de la estación..$^{2}$

28. ARAMC, Manuscrits, Francisco Salvá, «Tablas Meteorológicas», 4 vols., 1780-1784, vol. 1, 1793 «Resultado», s./f.

29. Idem.

30. AHCB, Fons Consell de la Ciutat i Ajuntament Modern, Acords, 1793, 1D. I-76, f. 164 r.

31. ARAMC, Manuscrits, Francisco Salvá, «Taules meteorològiques», 4 vols., 1780-1784, 1794 «Resultado», s./f.

32. Idem. 
Por otra parte, a la sequía primaveral y a la excesiva pluviosidad estival, se añadirían las consecuencias de una nueva anomalía, la térmica, en el estío, tal como refleja Francisco Salvá, quien admitía que «el estío empezó muy riguroso en el julio, cuyo calor fue excesivo y superior al que se ha observado en este mes desde el año 1780». ${ }^{33}$

La inestabilidad del clima, de las constantes pérdidas de las cosechas y de los efectos de las fiebres dio como resultado un contexto de precariedad extrema para la población barcelonesa. Una tendencia, la del empobrecimiento progresivo de la sociedad y la de la pérdida de la capacidad productiva por causa del debilitamiento de la sociedad, que condujo a que el capitán general de Cataluña comunicase, el 31 de julio de 1794, la suspensión de pagos, ya que habían tenido que suprimirse «por estar casi enteramente parado todo industrial, por la pésima cosecha, por la falta de operarios y trabajadores y, sobre todo, por la falta de dinero». ${ }^{34}$ De hecho, nos encontramos ante un contexto social en el que las gentes apenas tenían medios, como destaca el capitán general, para «mantenerse, a sí; ni a sus familias» ${ }^{35}$ debido a las «miserias insinuadas, y la de las enfermedades que le oprimen [al pueblo]». ${ }^{36}$

\section{La epidemia de sarampión de 1793 a través del testimonio de Francisco Salvá y Campillo}

La epidemia de sarampión, enfermedad infecciosa generada por un virus que se transmite entre personas ocasionando erupciones en la piel en forma de manchas de color rojo (Vargas-Soler et al. 2020: 30), que cundió entre la población infantil, desde mayo de 1793 hasta mediados de julio, constituye la antesala de la epidemia de fiebres, de la que trataremos más adelante, y cuyos efectos persistieron hasta finales de octubre. Aunque Francisco Salvá admite que estos perduraron incluso en 1794, aunque con un carácter más esporádico, pues «si bien no han dejado de verse enfermos con él [el sarampión] hasta en el junio de 1794; juro como eran muy pocos, no merecen el nombre de sarampiones epidémicos». ${ }^{37}$

Sin embargo, no fueron únicamente las criaturas, las que padecieron sus efectos, pues «con todo se vieron con él muchachos de 14, y jóvenes de 30 años de edad» ${ }^{38}$ e incluso se señalaba que la enfermedad cundió entre los neonatos, resultando destacable el caso en el que Salvá vio «nacer pintado del sarampión un niño, que pudo sacarlo de su madre, que le parió estando con él [el sarampión], y era señora de 25 años». ${ }^{39}$

33. Idem.

34. Archivo Histórico Nacional, diversos-colecciones, 160, núm. 51, «Correspondencia remitida a los capitanes generales de Cataluña por diversas personas e instituciones de los años 1794 y 1795», pp. 3-4.

35. Idem.

36. Idem.

37. ARAMC, Manuscrits, Francisco Salvá, «Taules meteorològiques», 4 vols., 1780-1784, «Epidemia de sarampión de 1793», s./f.

38. Idem.

39. Idem. 
En cuanto a los síntomas por los que se manifestaba la enfermedad, estos se hallaban precedidos por los de un catarro a los que se añadían «la salida en unos [d] el garrotillo, en otros la diarrea, vómitos en algunos y no faltaron quienes tuvieron ambas cosas a modo de un cólera morbo», para después empezar a manifestarse el sarpullido, sin descender la fiebre, «hasta haberse pintado la mayor parte del cuerpo, y en muchos no cesaba [la fiebre] hasta haber acabado de salir el sarampión, y entonces quedaban limpios de ella».40 Era una erupción que se extendía por el cuerpo de los afectados, acompañada por fuertes fiebres, que perduraba entre «24, 36 o 48 horas, subsistía también otras tantas, según la variedad de sujetos; de suerte que en unos empezaba a amortiguarse después de 24, 36 o más horas». ${ }^{41}$

Por otra parte, hallamos casos en los que se hallaban afectadas las criaturas por fiebre remitente que cedían, según el médico, mediante la aplicación de laxantes o en otros a través de la «corteza del Perú, dada en polvos, en extracto, o en tintura, según se podía hacer tomar a los chicos». ${ }^{42}$ Métodos curativos que se complementaban mediante la aplicación sistemática de las sangrías, en especial, aquellos casos en que la enfermedad se manifestase de forma acusada en sus primeras etapas. Asimismo, se complementaba el tratamiento con la aplicación de remedios paliativos consistentes en la ingesta de refrescos o baños con la finalidad de hacer descender la fiebre. En este sentido, establecemos la hipótesis de la posible combinación del sarampión con las fiebres palúdicas endémicas en la región, como también señala Jaume Codina en sus trabajos (Codina 1971; 1994; 2001; 2002). Más, si tenemos en cuenta, el apunte que realizó Salvá en mayo de 1793 cuando señalaba haber detectado entre sus pacientes las señales de unas «tercianas, que, aunque sin síntoma que las caracterizase de malignas, con todo por la intensidad de la fiebre, hacían acudir a la quina para cortarlas pronto y precaver las resultas». ${ }^{43}$

\section{Los efectos de las fiebres de 1793-1794 a través del testimonio de Francisco Salvá y Campillo}

La epidemia de sarampión que resultó en una alta mortalidad infantil entre los meses de mayo y septiembre de 1793 confluyó con el advenimiento de una nueva ola epidémica, en este caso de fiebres, que Francisco Salvá sitúa entre «últimos de diciembre de 1793 y primeros de enero de 1794». ${ }^{44}$ Una epidemia, cuyos inicios se enmarcan en la llegada de las primeras tropas procedentes del ejército del Rosellón y también de las gentes que huían del conflicto, ya que «varias personas venidas de allá y, especialmente, los prisioneros de guerra nos la transportaron». ${ }^{45}$ Eran tropas que procedían del Rosellón, pero que habían

\footnotetext{
40. Idem.

41. Idem.

42. Idem.

43. ARAMC, Manuscrits, Francisco Salvá, «Taules meteorològiques», 4 vols., 1780-1784, «Mayo 1793», S./f.

44. ARAMC, Manuscrits, Francisco Salvá, «Taules meteorològiques», 4 vols., 1780-1784, «Año 1794», s./f.

45. Idem.
} 
estado acantonadas en las zonas pantanosas del Ampurdán ${ }^{46}$ entre 1792 y 1793 , donde pudieron haber contraído el paludismo endémico propio de esa región para sumársele después el tifus, una enfermedad común de los ejércitos a raíz de las deficientes condiciones de higiene de las tropas y de sus campamentos.

Una enfermedad importada que pudo confluir con las fiebres endémicas que, en especial, eran comunes en la periferia barcelonesa. Pues ya entre julio de 1793 y junio de 1794 , Francisco Salvá destaca que a partir de septiembre de 1793 fue cuando inició a detectar las tercianas entre las «gentes venidas de fuera, con especialidad del ejército del Rosellón ${ }^{47}$ cuyas fiebres, tras ser tratadas con la quina en aquellos que las padecían, los dejaban «abatidos y postrados, pero no de modo que hubiese señas de malignidad, sino de fatiga y cansancio» ${ }^{48}$ La llegada masiva de tropas y de parte de la población procedentes del Ampurdán condujo a que los ciudadanos ofreciesen alojamiento en sus casas, salvo aquellos en los que por su estado de salud debieron ser atendidos en el Hospital de la Santa Creu. Estos dos factores fueron, según Salvá, la causa de la difusión de la enfermedad entre «los paisanos y eclesiásticos seculares, y regulares, de todas las comunidades y religiones de Barcelona que acudieron a asistirlos».49

Una epidemia cuyo punto álgido se produjo entre «febrero y hasta mediados de marzo ${ }^{50}$ para disminuir de forma progresiva hacia mediados de junio, donde «casi no se hablaba de ella». ${ }^{51}$ Fueron fiebres que, según el médico, se caracterizaban por ser calenturas de carácter esporádico, con síntomas iniciales que se correspondían a la enfermedad que, en la actualidad, conocemos como fiebres palúdicas. De hecho, la mayoría de las personas atendidas por Salvá experimentaban «pesadez, inapetencia, cansancio y desazón. Seguíanse [sic] los calosfríos [sic] uno o dos días, y después se descubría una fiebre con dolor de cabeza fuerte, a modo de un resfriado». ${ }^{2}$

Es así como apreciamos en los datos en bruto de mortalidad del Hospital de la Santa Creu (gráfico 3), que los militares atendidos, por la institución desde mediados de 1793, muestran un incremento en los decesos notorio entre los meses de octubre a diciembre. Pero resulta mayor la mortalidad que se detecta entre las tropas en los meses de enero (214 defunciones), febrero (166 decesos) y marzo (129 fallecimientos) de 1794, para descender hasta los 39 y 29 militares que perecieron en los meses de junio y julio, respectivamente.

Por otra parte, en relación con los síntomas, apreciamos como estos fueron, en los estados iniciales de la enfermedad, comunes a un resfriado. Lo que ocasionaba que los mé-

46. Véase la problemática de las fiebres en la región del Ampurdán (NE de la península Ibérica), en especial, en el contexto de las epidemias de fiebres de finales de los años ochenta del siglo xviI a través de los testimonios de los médicos Francisco Pons y Francisco Suñer en (Pometti, K. 2020).

47. ARAMC, Manuscrits, Francisco Salvá, «Taules meteorològiques», 4 vols., 1780-1784, «Año 1794», s./f.

48. Idem.

49. ARAMC, Manuscrits, Francisco Salvá, «Taules meteorològiques», 4 vols., 1780-1784, «Calentura epidémica en Barcelona en 1793 y 1794», s./f.

50. Idem.

51. Idem.

52. Idem. 


\section{Gráfico 3}

\section{Datos en bruto de mortalidad en el Hospital de la Santa Creu i Sant Pau de Barcelona, entre 1793 y 1795}

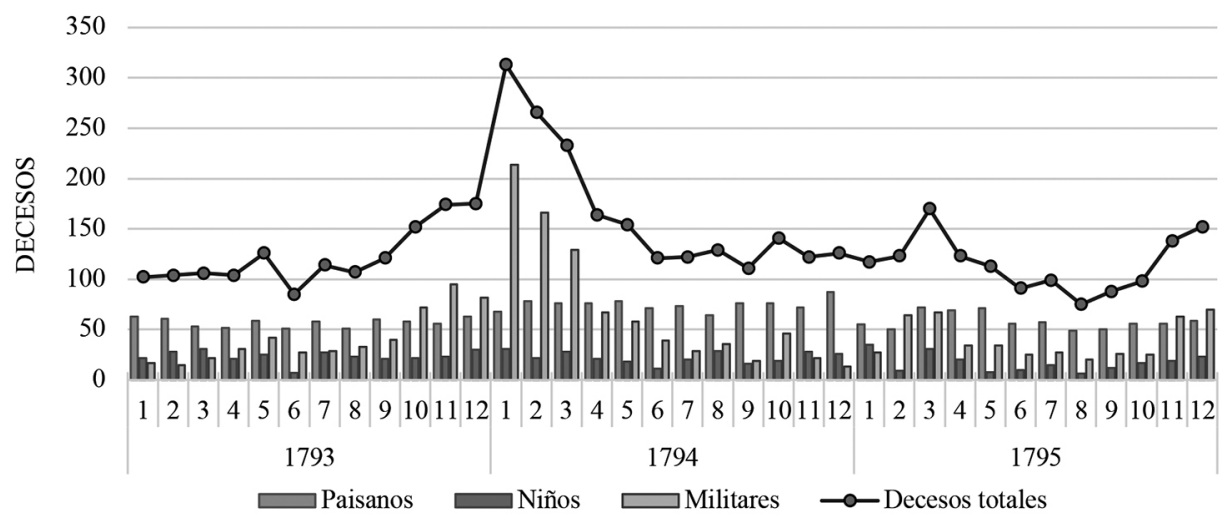

Fuente: elaboración propia a partir de ARAMC, «Papeles del Dr. D. Francisco Salvá», legajo XII, n. ${ }^{\circ}$ 1, «Notas para las tablas necrológicas de 25 años, en Barcelona, años 1780-1824», doc. 2. «Relación de los niños que han muerto en este Sto. Hospital de la Santa Cruz de Barcelona desde 1 de enero de 1780 hasta 31 de diciembre de 1803»; doc. 3 «Relación de los paisanos que han muerto en este Sto Hospital...»; doc. 4 «Relación de los militares que han muerto en este Sto. Hospital...».

dicos menoscabasen la gravedad de la situación hasta que tras 36 o 48 horas, se manifestasen los primeros signos del morbo:

Rompieron en sudor [los pacientes], y se limpiaron completamente de ella [de la fiebre], perseverando así uno, dos o tres días, con solo el dolor de cabeza, o con inapetencia, lengua sucia u otro síntoma que hacía ver que no estaban perfectamente buenos, y después les acometió nuevamente la calentura con frío. ${ }^{53}$

Tras los primeros signos de la enfermedad, era a partir de la segunda semana cuando los síntomas más graves se manifestaban de forma contundente, pues:

Los pulsos se oscurecían, la cabeza se ocupaba, padecían un coma vigil [sic], la barriga se embutía, sobrevenían los saltos de los tendones, hipo y aún convulsiones de todo el cuerpo, la lengua se secaba, se formaban grietas en ella, con ribete negro en los dientes, la respiración se notaba laboriosa. ${ }^{54}$

A partir de esta etapa, los que padecían las fiebres experimentaban una erupción característica del tifus exantemático, una enfermedad que puede presentarse de forma simultánea y sinérgica junto al paludismo acentuando los efectos de este último (Sallares

53. Idem.

54. Idem. 
2005: 201 y 2002 :127; Cox 2001: 26; Baba et al. 2013: 51-59; Druilhe 2005: 360; Wade et al. 2010: 577-581). Para Salvá, la presencia de la erupción era un elemento indicador de la mejoría en el curso de la dolencia, pues según el médico «se apagaba dicha eflorecencia [sic] muchos días antes de acabar la enfermedad». ${ }^{55}$ Por otra parte, hallamos que los que sobrevivían al morbo padecían posteriormente secuelas que los dejaban «sobremanera abatidos y postrados, aún aquellos que no la tuvieron muy grave, o en quienes los síntomas no tomaron mucho incremento». ${ }^{56}$

En cuanto al tratamiento de las fiebres, este consistió en el uso sistemático de sangrías y de purgas, en la aplicación de vomitivos y, únicamente en aquellos casos de mayor gravedad, se recurría a la quina o el alcanfor. Sin embargo, hallamos casos en los que los médicos promocionaban métodos aparentemente exitosos como los empleados por el doctor Lorenzo Font, quien aseguraba tener la «particular satisfacción, de que treinta y tantos militares y paisanos que han venido del ejército del Rosellón, a quienes he asistido ${ }^{57}$ habían sanado sin recurrir a preparaciones medicamentosas. Unas afirmaciones que podían deberse a la respuesta cíclica de las tercianas. Es decir, que la aparente curación de los enfermos, sin recurrir el médico ni a la quina u otros remedios que eran a las soluciones más comunes (purgas, sangrías o la administración de refrescos) podrían deberse a los ciclos naturales del paludismo, en los que la enfermedad pasaba a una fase latente o asintomática en los pacientes antes de desarrollar nuevos síntomas.

\section{La incidencia de las fiebres en el Real Hospicio de Barcelona en 1794: ¿Una enfermedad importada?}

La Topografía del departamento destinado para las mujeres en el Real Hospicio de Barcelona, y epidemias observadas en el 1787 y 1794 elaborada por Francisco Salvá, constituye la primera realizada en la ciudad de Barcelona y la que nos permite analizar la percepción y el impacto de la epidemia en el Hospicio de mujeres ubicado en la Casa de la Misericordia.

Unas fiebres que se extendieron de forma sincrónica a las que sucedían en el resto de la urbe, pero con una especial incidencia en el Hospital de la Santa Creu. Pues fue en marzo de 1794 cuando se detectaron también en el Hospicio, al empezar a «enfermar varias muchachas del departamento destinado para ellas en este Real Hospicio» (Salvá 1798: 438). Una epidemia cuyas causas mayores, además de las condiciones climáticas, atribuye tanto a la falta de limpieza de las tropas alojadas en el Hospital como a la falta de higiene de los alojamientos en que moraban las muchachas del Hospicio. Sin embargo, la reflexión de Salvá deja entrever la repercusión que pudieron generar las fiebres entre las tropas francesas, en el transcurso de su retirada, entre los primeros días de agosto e inicios de sep-

55. Idem.

56. Idem.

57. AHCB, CDH15, Diario de Barcelona, núm. 67, sábado 8 de marzo de 1794, «Discurso sobre la actual epidemia de calenturas pútridas», pp. 265-266. 
tiembre, un período en el cual los tercianarios abundaban entre las filas del ejército napoleónico, el cual se hallaba mermado no únicamente por las bajas ocasionadas por la contienda sino por los «muchos tercianarios que tenía» (Salvá 1798: 444-445). Asimismo, el médico destacaba la endemicidad de las fiebres en el Ampurdán condicionadas por las características del medio pantanoso (Pujiula 2008: 63; Surroca i Sens 1979) presente en dicho espacio y también por la variabilidad del clima, las que no estaban únicamente vinculadas a las enfermedades propias de los ejércitos (tifus, escorbuto, sífilis, entre otras afecciones) sino las «tercianas benignas y ligeras, que son endémicas en aquel terreno» (Salvá 1798: 445).

No obstante, nos hallamos ante una epidemia que afectó por igual tanto a los habitantes de la región, como a los militares asentados en aquel territorio y cuya intensidad resultó inusual en comparación con los recurrentes embates endémicos de las fiebres, pues:

Sin embargo, como las cogieron casi todos, aunque aclimatados y naturales del país, y esto no solo los que volvieron a él, sí también los que se quedaron allá; como no perdonaron a los niños de pecho que suelen vivir al abrigo de las influencias del aire, o muy poco expuestos a ellas como subsistieron y acometieron de nuevo [las fiebres] a varios en el mes de octubre (Salvá 1798: 445).

Una epidemia, cuyos efectos fueron también sentidos en el Hospicio de Barcelona, en la Casa de la Misericordia, como apuntamos, entre últimos de abril y primeros de mayo. Un período en el que, según Salvá, llegaron a tener hasta setenta enfermas entre seiscientas muchachas, y que perduró hasta finales de mayo de 1794, momento en que fue mermando hasta quedar extinguida a mediados de julio. Las fiebres, recayeron sobre las mujeres de mayor edad, las que convivían en una sala «sobrecargada de gentes» (Salvá 1798: 445) en deficientes condiciones de salubridad como resultado de la «reunión de muchas muchachas en las piezas de dormir y de trabajar» (Salvá 1798: 445). Asimismo, las mujeres de entre diez y catorce años padecieron las fiebres en formas más graves, resultando menor la incidencia de estas entre las niñas y las mayores de veinticinco años.

Los síntomas revelan ser muy próximos a los de una infección palúdica en la que, además, hallamos signos de una posible coinfección por lombrices parasitarias. Elementos que se unieron al aturdimiento, a los dolores de cabeza y a los vómitos que conformaban el cuadro clínico de las afectadas por la epidemia. Pero el signo más característico de la infección palúdica lo hallamos en que sus síntomas bajaban «insensiblemente dos o tres días, después la fiebre tomaba incremento algunas horas, les acometía frío y rigor, echaban a sudar copiosamente, y antes de las veinte y cuatro horas de esto, quedaban limpias de fiebre» (Salvá 1798: 439).

El hecho de que el médico atribuyera un carácter contagioso a la enfermedad podría responder a los ciclos palúdicos que reflejaban parte de las enfermas. Pues, tras remitir las fiebres en los primeros días se constataban las recaídas de las muchachas del Hospicio que habían quedado convalecientes en la misma sala que el resto de las afectadas (Salvá 1798: 449). Es más, la frecuencia con las que las mujeres recaían de nuevo en los ciclos febriles se produjo, según Salvá, en dos terceras partes de las internas e incluso en las que habían sido redirigidas al Hospital de la Santa Creu debido a la gravedad de su cuadro clínico (Salvá 1798: 441-442). 
Fiebres que volvían a repercutir de nuevo, pero con mayor duración y virulencia a medida que se sucedían los embates de la enfermedad, aunque se producían también recaídas más benignas. De hecho, el médico constata que «en varias, la recaída fue más violenta que la primera o segunda calentura, en otras, al contrario, y esto fue lo más común» (Salvá 1798: 442).

De hecho, la extrema debilidad de las pacientes se debía tanto al proceso febril, como a la coinfección de lombrices intestinales que muchas de ellas presentaron. Además, debemos añadir que, debido a las limitaciones económicas del Hospicio, tal como remarca Salvá «la falta de medios, o de fondos de la casa obligó a escoger el más sencillo [método curativo], y los remedios más baratos que supe hallar» (Salvá 1798: 447). Es decir, que tuvo que limitarse a proveer a las enfermas de infusiones y caldos. En concreto, el tratamiento se tuvo que limitar a la administración de «una infusión de borrajas en frío, en la que se echaba oximel, y de esta bebían a pasto hasta el día siguiente, manteniéndose con substancia de pan cada cuatro horas» (Salvá 1798: 439) para, al día siguiente, aplicárseles vomitivos y, en caso de que estos no sanasen a las enfermas o mitigase sus síntomas, se recurría a otra infusión de «borrajas con oximel, y un grano de tártaro emético» (Salvá 1798: 440).

La aplicación sistemática de vomitivos sí que pudo contribuir a la remisión del malestar en las pacientes examinadas por Salvá, pues estas mediante la ingesta de un «cocimiento de yerba de Mallorca (corrallina) [...] arrojaban muchas lombrices, y calmaban los síntomas de desmayos, dolores fuertes de barriga» (Salvá 1798: 441).

\section{Los temores ante el contagio: la reacción ciudadana}

El recelo, el temor al contagio, constituyó una reacción frecuente entre la población barcelonesa entre estos años. A modo de muestra, las cartas anónimas dirigidas al editor del Diario de Barcelona, entre el 14 y el 29 de marzo de 1794, reflejan con claridad la percepción de la población ante el miedo al contagio.

La primera de ellas, con fecha de 14 de marzo, transmite la sensación de pánico que había cundido entre la población debido a la propagación de rumores, resultando necesario aclarar que las enfermedades que se experimentaban en la ciudad no tenían un carácter contagioso. Es más, el testimonio de este escrito, nos permite detectar que las fiebres se extendieron, especialmente, entre quienes se dedicaban al cuidado y sanación de los enfermos. Pues:

A pocos días de haberse amontonado enfermos en nuestro Hospital General, por los motivos en que no debo entrar, cayeron malos los Hermanos de la Caridad, o los enfermeros, los practicantes de cirugía, los médicos, y los sacerdotes asistentes. Se acudió a las Órdenes Religiosas para la asistencia espiritual y temporal, que acudieron como a porfía a aquella casa, (hecha ya una cloaca de infección), para consolar a los enfermos, limpiarlos, y vaciar los vasos inmundos..$^{58}$

58. AHCB, CDH15, Diario de Barcelona, núm. 73, viernes 14 de marzo de 1794, p. 290. 
Pero los efectos de la epidemia no recayeron únicamente sobre las órdenes religiosas, sino también en las casas de los particulares, entre «los parientes o interesados de los infelices que, sobre haberles asistido, han estado con el sentimiento de perderlos, con el temor de su muerte, y con la fatiga de velarlos, han cogido la calentura». ${ }^{59}$ Sin embargo, el testimonio de la carta anónima, expone los casos en que tanto el personal del Hospital como las expósitas no contrajeron la enfermedad para justificar que no se trataba de un morbo contagioso, pues según este «la cosa no es tan fiera como nos la pintan, y abultan algunos genios tétricos, que parece se complacen en afligirnos [...] que es del caso de poner ese terror pánico, de que están temblando varios». ${ }^{60}$ Era el pánico y el miedo lo que el autor quería mitigar a través de su escrito, pues si se reducía el temor de la población a considerar la enfermedad contagiosa que se había extendido tras oír la población «frecuentemente la campana de viáticos», ${ }^{61}$ se conseguiría que «las gentes no se negaran a asistir a los enfermos, y a visitarlos». ${ }^{62}$ Aquí, observamos, según el testimonio, la extensión del miedo entre la población hasta el punto de negarse esta a prestar atención a los enfermos y abandonarlos en el desarrollo de su afección.

La respuesta la hallamos en 29 de marzo, donde se ratifican los razonamientos expuestos en la primera, según los cuales el temor de la población se fundamentaba en la falta de información en relación con el riesgo de contagio. Fiebres, las de 1794, cuyos efectos resultaban conocidos por estar vinculadas a los ejércitos y conocerse estas como «enfermedades de campaña» o «enfermedades de hospital», y que habían generado consecuencias remarcables entre el ejército del duque de Brunswick en las campañas bélicas de la Primera Coalición hasta obligarle a salir de Francia. Eran las mismas fiebres que «vemos todavía en los ejércitos aliados del norte, en los ejércitos franceses, y en el nuestro del Rosellón» ${ }^{63}$ y que, según reconocía el autor de la segunda carta «de los ejércitos se comunican con facilidad estas enfermedades a los pueblos vecinos, y principalmente a los que son de tránsito», ${ }^{64}$ por lo que era necesario concienciar a la población de que las fiebres «deben contarse entre los males inseparables de la guerra, y que únicamente puede detenerse su propagación por medio de una buena policía».5

Si las fiebres no se habían extendido más allá del Hospital, según el redactor de la carta, se debía a la aplicación de medidas de contención epidémica basadas en recluir a los enfermos y en aplicar remedios paliativos, lo que explicaba «el que sanen muchísimos más que no mueren». ${ }^{66}$ De hecho, las fiebres palúdicas se caracterizan por causar tasas de mortalidad bajas o moderadas en la población, con mayor impacto sobre la población infantil. El hecho de que los habitantes de la urbe escuchasen la campana de viático se debía a los

59. AHCB, CDH15, Diario de Barcelona, núm. 73, viernes 14 de marzo de 1794, pp. 290-291.

60. AHCB, CDH15, Diario de Barcelona, núm. 73, viernes 14 de marzo de 1794, p. 291.

61. Idem.

62. Idem.

63. AHCB, CDH15, Diario de Barcelona, núm. 88, sábado 29 de marzo de 1794, pp. 349-350.

64. AHCB, CDH15, Diario de Barcelona, núm. 88, sábado 29 de marzo de 1794, p. 350.

65. Idem.

66. Idem. 
enfermos que, cursando la enfermedad en sus casas, recibían la extremaunción ante el posible riesgo de perecer. Es así como la relativa benignidad de las fiebres se traducía en un incremento del temor, del miedo al contagio entre una población que escuchaba con frecuencia los toques de una campana que «toca a Viático [que] es un termómetro muy infiel en el día, para calcular por ella los estragos de esas enfermedades». ${ }^{67}$

Este pánico derivaba en las anteriormente comentadas actitudes de rechazo a mantenerse próximo a los enfermos y a que los barceloneses evitasen acudir al Hospital de la Santa Creu en busca de un tratamiento, ya que consideraban que era un punto de infección. Lo que condujo a que las gentes permaneciesen en sus casas. Enfermos que «estarían otro tiempo en el Santo Hospital, donde no van ahora, porque neciamente preocupados, tienen por segura la muerte, y más quieren pasarlo como puedan en su casa; y así es preciso administrarles en ella los Santos Sacramentos». ${ }^{68}$ Por esta razón, era que «se oye más la campana de las parroquias, porque toca menos la del Santo Hospital». ${ }^{69}$

Otra de las reacciones de la población como resultado del miedo al contagio, la hallamos en las quejas que dirigieron Francisco Pontes, Juan Bacigallupe, Josep Volta, Josep Capmany, Pablo Janer y Josep Fontseré, vecinos de la calle Tarongeta, a la Junta de Sanidad de Barcelona el 29 de julio de 1794 (figura 1).

Estos, centrados en las causas higiénicas, exponían los perjuicios que debían soportar debido a la ventilación de los paños procedentes del Hospital. Una tarea que recaía en ese momento en Salvador Pascual, quien disponía de un almacén para esta finalidad. Una labor que ocasionaba, según los demandantes, graves perjuicios al vecindario y a la salud pública de la urbe, debido a la «imponderable incomodidad que les sigue, y a sus familias por el fatal vapor que exhala dicho almacén por el infecto género de trapos pútridos que encierra». ${ }^{70}$ Un espacio ante el que previamente habían intentado hallar una solución pactada para evitar acudir a la Junta de Sanidad pero que atentaba contra el principal sustento de Salvador. Es más, ante la insistencia de los vecinos, estos exponían que «aún ha tenido Pascual el extraordinario valor de decir públicamente, y en presencia de varias personas de carácter, que él continuaría en introducir sus pestíferos trapos en dicho almacén y evaporarles cuando le acomode». Una tarea que señalaban como una amenaza para la salud de los ciudadanos ante las «fatales enfermedades que cunden en el día, y de mucho tiempo en esta capital».

Para hallar una solución exponían que el almacén debía trasladarse tanto por lo nocivo de su contenido como por la suma estrechez de la calle. Alegaban que a Pascual no le resultaría demasiado complicado hallar algún otro lugar, más alejado, pues «la calle Tarongeta es muy estrecha, las casas muy altas, de consiguiente, luego que Pascual abra su almacén, se siente notablemente su fetor».

67. Idem. En este sentido, apuntamos a los trabajos de Martí Gelabertó Villagrán acerca de la importancia taumatúrgica del tañido de las campanas para indicar a la población la importancia de determinados acontecimientos.

68. Idem.

69. Idem.

70. Incluida esta, todas las citas que seguidamente insertaremos, proceden de AHCB, Sanitat, 1L. VI-19, Lligall de representacions, 1794-1796, 19 de julio de 1794, s./f. 


\section{Figura 1}

\section{Ubicación de la calle Tarongeta}

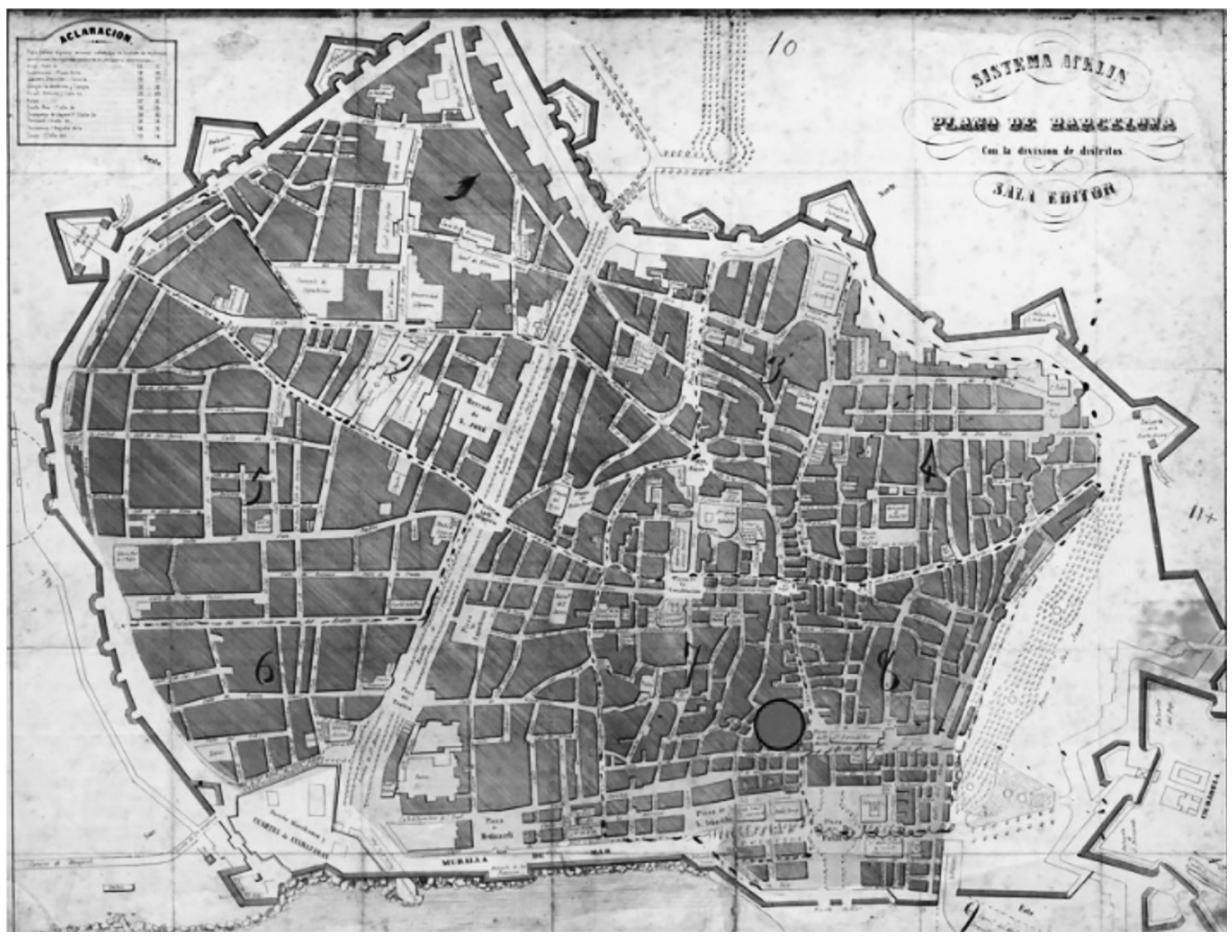

Fuente: elaboración propia a partir de AHCB, Secció Gràfics, núm. 03018, «Plano de Barcelona con la división de distritos», Sala Editor, 1854.

El 18 de agosto, el doctor Buenaventura Casals, residente en las inmediaciones del almacén, lideró las quejas de la vecindad, pues exponía en su dictamen «lo muy expuesta que se halla su salud, la de su familia y vecindario en consecuencia de permitir el dejar depositar trapos en el almacén que está bajo su habitación». No era una situación nueva, pues los médicos de sanidad ya habían indicado las contraindicaciones, en materia de salud pública, que se desprendían de la actividad realizada en este tipo de almacenes, para lo que «fueron oídos a consulta por mandato de Vuestra Señoría una y otra vez». Además, las normativas en torno a la gestión de los trapos, enseres o cualquier posesión de una persona aquejada por una enfermedad contagiosa habían sido objeto de repetidas normativas sanitarias que restringían y regulaban la actividad, además del control de la calidad y procedencia de los alimentos, de la polución industrial y otros asuntos, en especial durante los años finales de la década de los ochenta del siglo xviII (Zarzoso 2003: 46; Jori 2012: 532-535).

Sin embargo, era el miedo al contagio lo que se sumaba a los posibles riesgos en materia de salud pública para reforzar los argumentos de los demandantes en torno al impac- 
to que podría tener el hecho de seguir permitiendo la actividad del almacén en la calle Tarongeta, más si tenían en consideración «si a esto se añade cuan general ha sido, lo es, y muy contingente de poder ser, la catástrofe de las calenturas malignas castrenses». ${ }^{71}$ Una situación problemática a la que cabía añadir el poco cuidado con el que Pascual realizaba la limpieza de los residuos que se acumulaban en la alcantarilla del almacén, la cual efectuaba «en tiempo de excesivos calores (como si no fuese bastante para infectarlos el hedor de los trapos que contiene el almacén)» hecho que generaba una aún mayor incomodidad ante el vecindario, por lo que se instaba a que la Junta de Sanidad ordenase que se abstuviera de «semejante extracción; y en el caso de ser necesario por la poca capacidad de dicha alcantarilla, se le mande profundizarla a fin de que pueda esperarse en el tiempo proporcionado y menos expuesto».

El 22 de septiembre, la Junta de Sanidad resolvió a favor de los vecinos. En la resolución resultan evidentes los temores ante cualquier posible elemento que ayudase a extender la enfermedad. En el inicio de su respuesta remarcaban que eran «los calores, las enfermedades que tanto han cundido en esta ciudad y de que no se ve aun enteramente libre» las causas que habían pesado en el momento de dictar su resolución. La cual consistía en trasladar el almacén al lugar ofrecido por el doctor Casals, en la Barceloneta para evitar «que se propague alguna infección sino mayor, a lo menos igual, a la que se ha padecido este año».

Pero la solución propuesta no fue de la conveniencia de Pascual. Además, este obstaculizó la aplicación de la resolución con la finalidad de «persuadir de que hay otros almacenes en la ciudad llenos de igual calidad de trapos con licencia, y consentimiento de esta Junta, y de todo infiere con absoluta aserción que está ella complicada en las particulares miras del Dr. Casals». A lo que la Junta de Sanidad respondió que «hará sin duda la justicia que cree merecer esta Junta de que solo se han despreciado los requerimientos verbales que hizo Pascual al portero» aplicando para ello «todo el celo que debía tener esta Junta para evitar los daños que la detención de este asunto puede causar» instando a obligar a Salvador Pascual a «trasladar en paraje menos expuesto los trapos de que tanto se quejan los vecinos».

\section{Conclusiones}

Los años 1793 y 1794 se insertan en una dinámica de inestabilidad climática que probablemente contribuyó a los severos impactos tanto en el plano económico como entre la salud de la población que produjeron efectos notorios sobre la sociedad. Las consecuencias sobre el medioambiente producidas por la irregularidad de la oscilación Maldà fueron notables, entre 1760 y 1800, pero especialmente perjudiciales en los últimos años del siglo xviI. Fue un período en el que, además, se adjuntaban las consecuencias que producían de forma directa e indirecta las actividades productivas humanas (cultivo de cáñamo,

71. Idem. Para mayor información sobre la gestión del miedo y su importancia en situaciones de carácter extremo véanse los trabajos de Jean Delumeau. 
irrigación intensiva, deficientes sistemas de alcantarillado, etc.), tanto sobre el medio como sobre la salud urbana, que se adjuntaban a la inestabilidad climática en un período en el que se sucedían rápidamente e incluso de forma simultánea, períodos de sequías severas con episodios de lluvias torrenciales. La combinación de este sustrato humano y ambiental daba lugar a espacios inundados, en el interior y exterior de las poblaciones, que generaban condiciones de salubridad deplorables. En el caso de Barcelona, los años de 1793 a 1794, están introducidos en una dinámica ambiental caracterizada por importantes oscilaciones de precipitación, desde 1788 a 1793. Resultando los años más irregulares, los de $1788,1789,1790,1791$ y 1792. Esta fluctuación constante entre sequías e inundaciones produjo una notoria escasez del producto agrícola y también una creciente preocupación entre la población, como pudimos apreciar en las solicitudes de los prohombres del gremio de labradores de Barcelona para que se celebrase rogativas pro pluvia, a partir del 5 de abril de 1791. La búsqueda de nuevos recursos hídricos constituyó una de las preocupaciones del ayuntamiento, iniciativas que topaban con limitaciones de corte económico para poder ser realizadas de forma satisfactoria. El abasto del trigo resultó uno de los problemas más acuciantes para el consistorio barcelonés, especialmente, entre los años 1793 y 1794. Ante la falta de recursos económicos para proveer de alimento a la población se recurrían a dotaciones económicas extraordinarias recabadas de colectas benéficas, a la vez que, bajo la supervisión de los médicos de Sanidad, se confeccionó una nueva variedad de pan, de menor calidad, pero que ofrecía un sustento paliativo para la hambrienta población barcelonesa. Fue un período en el que además de la escasez provocada por la sequía persistente, las lluvias torrenciales afectaban seriamente a las infraestructuras esenciales de la ciudad. Un período al que se adjuntaron las consecuencias derivadas de la guerra de la Convención. Barcelona, había ya padecido los efectos de las fiebres en la década de los ochenta del siglo xviı, pero la llegada constante de población desplazada por el conflicto y de tropas, procedentes del Rosellón y acantonadas anteriormente en el Ampurdán, comportó la importación de fiebres palúdicas y tifoideas. A estas, les habían sucedido epidemias de sarampión de mayo a octubre de 1793 recayendo, en su mayor parte, sobre la población infantil.

El análisis de los efectos generados por las fiebres palúdicas a través del testimonio de Francisco Salvá nos hace posible observar los síntomas tanto de los ciudadanos como de los militares que las padecieron con una mortalidad especialmente elevada en el Hospital de la Santa Creu en los meses de enero, febrero y marzo de 1794. Si bien, las fiebres también repercutieron sobre colectivos desfavorecidos que vivían en precarias condiciones de higiene y con recursos económicos limitados como fueron las mujeres del Real Hospicio, ubicado en la Casa de la Misericordia. Las muchachas padecieron los embates de las fiebres con mayor virulencia y constantes recaídas, combinadas con coinfecciones por lombrices parasitarias y cuyo tratamiento de los síntomas se limitó a los métodos curativos más sencillos (infusiones, caldos) y los remedios curativos más económicos.

La reacción ante la posibilidad de contraer la enfermedad se tradujo en el temor al contagio de la población, como pudimos apreciar a través de las cartas anónimas insertas en el Diario de Barcelona, entre el 14 y el 29 de marzo de 1794, en las que se debatía sobre 
este asunto. A la vez que pudimos entrever cómo la mayor parte de la ciudadanía evitaba acudir al hospital y cursaba la enfermedad en sus casas, temiendo incluso morir a causa de las fiebres. Los temores y recelos al contagio incluso se tradujeron en denuncias a la Junta de Sanidad de la urbe por actividades, como la ventilación, almacenamiento y limpieza de los trapos procedentes del hospital, que culminaron en pleitos hacia quienes se dedicaban a esta actividad, ofreciéndose, a modo de solución, el traslado de los almacenes a parajes más deshabitados o alejados de la urbe, propuesta que no fue aceptada, en el caso de Salvador Pascual.

Esta investigación ha puesto de relieve la interconexión entre las causas climáticas, ambientales y sociales que se produjeron a finales del siglo xviI, y de cómo la combinación de estas favoreció el sustrato, junto con los acontecimientos históricos, para el arraigo de enfermedades importadas y endémicas ante las que la sociedad ofrecía medios de contención limitados por su contexto histórico, científico-técnico, que podrían haber sido más efectivos si hubiesen dispuesto de la dotación económica necesaria para ponerlos en funcionamiento, en especial en el caso de las mejoras necesarias en la infraestructura hídrica o en el aprovisionamiento de trigos en épocas de escasez.

\section{Bibliografía}

Alberola Romá, A. (1985). «Una enfermedad de carácter endémico en el Alicante del xviII. Las fiebres tercianas», Revista de Historia Moderna. Anales de la Universidad de Alicante, núm. 5, pp. 127-140.

Alberola Romá, A. (1989). «La bonificación de enclaves insalubres en el País Valenciano durante la Edad Moderna: el ejemplo de la laguna de la Albufereta (Alicante)», Investigaciones geográficas, núm7, pp. 69-81.

Alberola Romá, A. (2010a). Quan la pluja no sap ploure. Sequeres i riuades al País Valencià en l'Edat Moderna. València: Publicacions de la Universitat de València.

Alberola Romá, A. (2010b). «El clima «trastornat»: sequera, temporals, riuades i inundacions a Catalunya i al País Valencià a les acaballes del segle xvıI», Estudis d'història agrària, vol. 23, pp. 301-317.

Alberola Romá, A. (2012). «Un "mal año" en la España del siglo xviII. Clima, desastre y crisis en 1783». En X. HuETz de Lemps y J. P. Luis (eds.). Sortir du labyrinthe. Études d'histoire contemporaine de l'Espagne. Madrid: Casa de Velázquez, pp. 325-346.

Alberola Romá, A. (2014). Los cambios climáticos: la pequeña Edad del Hielo en España. Madrid: Cátedra.

Alberola Romá, A. (2018). «De desastres varios y epidemias. El abandono forzoso de poblaciones en el Mediterráneo español durante el siglo xviI». En M. RodríGuez Cancho y J. P. Blanco Carrasco (coords.). Migraciones y movilidad social en la época moderna. Madrid: Sindéresis, pp. 22-47.

Alberola Romá, A. (2019). «Paisatge, clima, perill, por i patiment: una ullada al Mediterrani occidental a l'època moderna», Pedralbes, núm. 39, pp. 83-119. 
Alberola RomÁ, A.; Bernabé Gil, D. (1999). «Tercianas y calenturas en tierras meridionales valencianas: una aproximación a la realidad médica y social del siglo xviI». Revista de Historia Moderna. Anales de la Universidad de Alicante, núm. 17, pp. 95-112.

Alberola Romá, A.; Box Amorós, M. (2016). «Sequía, temporales y cosechas deficitarias en el nordeste peninsular: un apunte de las consecuencias del "mal año" de 1783 en algunos corregimientos aragoneses y catalanes». En J. Olcina Cantos y A. M. Rico Amorós (coords.). Libro Jubilar en Homenaje al Profesor Antonio Gil Olcina. Sant Vicent del Raspeig: Instituto Interuniversitario de Geografía, Universidad de Alicante, pp. 845860 .

Alberola Romá, A.; Pradells Nadal, J. (2012). «Sequía, inundaciones, fiebres y plagas en tierras aragonesas y catalanas (1780-1790)». En D. Bernabé y A. Alberola Romá (eds.). Magistro et amico. Diez estudios en bomenaje al Profesor Enrique Giménez López. Alicante: Publicaciones de la Universidad de Alicante, pp. 65-93.

ANÉs, G. (1974). Las crisis agrarias en la España moderna. Madrid: Taurus.

Alpert, P.; Baldi, M.; Ilani, R.; KrichaK, S.; Price, C.; Rodó, X. et al. (2006). «Relations between Climate Variability in the Mediterranean Region and the Tropics: ENSO, South Asian and African Monsoons, Hurricanes and Saharan Dust», Developments in Earth and Environmental Sciences, vol. 4, pp. 149-177.

Baba, M.; Logue, C. H.; Oberinde, B.; Abdulmaleek, H.; Williams, J.; Lewis, J. et al. (2013). «Evidence of arbovirus co-infection in suspected febrile malaria and typhoid patients in Nigeria», Journal of Infection in Developing Countries, vol. 7 (1), pp. 51-59.

Barriendos, M. (2000). «Recerques sobre l'evolució del clima a Catalunya durant els darrers set segles». En J. Vilà Valentí, (coord.). Medicina, medi ambient i clima. Investigacions punta per al 2000. Barcelona: Fundació Catalana per a la Recerca, pp. 153-216.

BarRIENdos, M. (2005). «Variabilidad climática y riesgos climáticos en perspectiva histórica. El caso de Catalunya en los siglos XvIII-XIX», Revista de Historia Moderna, vol. 23, pp. $11-34$.

Barriendos, M. (2007). «Variabilidad climática en España a escala plurisecular. Reconstrucción a partir de fuentes documentales históricas». En Consejería DE Medio Ambiente (Junta de Andalucía). El cambio climático en Andalucía: evolución y consecuencias medioambientales. Sevilla: Junta de Andalucía.

Barriendos, M.; Dannecker, A. (1999). «La sequía de 1812-1824 en la costa central catalana. Consideraciones climáticas e impacto social del evento». En J. M. Raso NADAL y J. MarTín VIDE. La Climatología española en los albores del siglo XXI. Barcelona: Asociación Española de Climatología, pp. 53-62.

Barriendos, M.; Gil-Guirado, S.; Pino, D.; Tuset, J.; Pérez-Morales, A.; Alberola, A. et al. (2019). «Climatic and social factors behind the Spanish Mediterranean flood event chronologies from documentary sources (14th-20th centuries)», Global and Planetary Change, vol. 182, núm. 102997, pp. 1-16. DOI: 10.1016/j.gloplacha.2019.102997.

Barriendos, M.; Gómez, L. (1997). «Análisis de la incidencia de la actividad volcánica en las temperaturas medias mensuales de Barcelona (ss. XVIII-XX)». En J. MarTín-Vide (ed.). Avances en climatología histórica en España, Barcelona: Oikos-Tau, pp. 47-62. 
Barriendos, M.; Llasat, M. Del C. (2003). «The Case of the 'Maldá' Anomaly in the Western Mediterranean Basin (AD 1760-1800): An Example of a Strong Climatic Variability», Climatic Change, vol. 61, pp. 191-216. DOI: 10.1023/a:1026327613698.

Betrán Moya, J. L. (2006). Historia de las epidemias en España y sus colonias 1349-1919. Madrid: La Esfera de los Libros.

Braudel, F. (1993). El Mediterráneo y el mundo mediterráneo en la época de Felipe II. Madrid: Fondo de Cultura Económica.

Brázdil, R.; Pfister, C.; Wanner, H.; Von Storch, H.; Luterbacher, J. (2005). «Historical Climatology in Europe-The State of the Art». Climatic Change, vol. 70 (3), pp. 363-430.

Bueno Vergara, E. (2014). Clima y medicina en el Alicante del siglo XVIII. Amenazas medioambientales, vulnerabilidad social y estrategias de resistencia. Alicante: Universidad de Alicante.

Bueno Vergara, E. (2017). «Fiebres tercianas, sequías y lluvias torrenciales en el Alicante del Setecientos», Revista de Historia Moderna. Anales de la Universidad de Alicante, núm. 35, pp. 377-409.

Bülent, A.; Kampen, H.; Fontenille, D. (2007). «Malaria in Southern Europe: resurgence from the past?». En W. TAKKen y B. G. J. KNols (eds.). Emerging pests and vector-borne diseases in Europe. Países Bajos: Wageningen Academic Publishers, pp. 35-57.

Burgueño, J. (2016). El Pla de Barcelona a la fi del s. XVIII. Respostes al qüestionari de Francisco de Zamora. Barcelona: Societat Catalana de Geografía.

Camuffo, D.; Bertolin, C.; Barriendos, M.; Domínguez-Castro, F.; Cocheo, C.; Enzi, S. et al. (2010). "500-year temperature reconstruction in the Mediterranean Basin by means of documentary data and instrumental observations», Climatic Change, vol. 101, pp. 169199. DOI: 10.1007/s10584-010-9815-8.

Castells Oliván, I. (1970). «Els rebomboris del pa a Barcelona», Recerques, vol. 1, pp. 51-81.

Casty, C.; Raible, C. C.; Stocker, T. F.; Wanner, H.; Luterbacher, J. (2007). «A European pattern climatology 1766-2000», Climate Dynamics, vol. 29 (7-8), pp. 791-805.

Codina, J. (1971). El delta del Llobregat i Barcelona. Gèneres i formes de vida dels segles XVI al xx. Barcelona: Ariel.

Codina, J. (1994). Inundacions al Delta del Llobregat. Barcelona: Dalmau.

Codina, J. (2001). El temps dels albats: contagi i mortalitat al Baix Llobregat. Lleida: Pagès.

Codina, J. (2002). La vida i la mort al delta del Llobregat: (segles XIV-XIX): qüestions de demografía bistórica. Barcelona: Viena.

Cox, F. E. G. (2001). «Concomitant infections, parasites and immune responses», Parasitology vol. 122, pp. 23-38.

Delumeau, J. (1978). La peur en Occident (xIve-Xvilie siècles). Une cité assiégée. París: Fayard.

Desarve, J. P. (1972). Médecins, climat et épidémies à la fin du xvile siècle. París: Mouton.

Domínguez-Castro, F.; Ribera, P.; García-Herrera, R.; Vaquero, J. M.; Barriendos, M.; Cuadrat, J. M. et al. (2012). «Assessing extreme droughts in the Iberian Peninsula during 17501850 from rogation ceremonies», Climate of the Past, vol. 8, pp. 705-722. DOI:10.5194/ cp-8-705-2012. 
Druilhe, P.; Tall, A.; SoKhna, C. (2005). «Worms can worsen malaria: Towards a new means to roll back malaria?», TRENDS in Parasitology, vol. 21 (8), pp. 359-362.

Espuche García, A. (2009). La Ciutat del Born: economia i vida quotidiana a Barcelona (segles XIV a XVIII). Barcelona: Ajuntament de Barcelona, Museu d'Història de Barcelona. Fabregat i Galcerì, E. (2006). L'impacte de l'arròs: el Delta de l'Ebre a la década del 1860. Benicarló: Onada edicions.

Figuerola i Pujol, I. (1982). Iniciación al estudio de la sanidad en Catalunya (1720-1800). Barcelona: Universidad de Barcelona, Facultad de Farmacia.

García Torres, A. (2017). «Extremismo climático y peligro biológico en el sureste español (1780-1800)», Revista de Historia Moderna. Anales de la Universidad de Alicante, núm. 35, pp. 345-376.

García Torres, A. (2018). Riesgo climático y desastre en tierras meridionales valencianas durante el siglo XVIII. Alicante: Universidad de Alicante, Servicio de Publicaciones.

Gelabertó Villagrán, M. (2005). La palabra del predicador. Contrarreforma y superstición en Cataluña (siglos XVII-XVIII). Lleida: Milenio.

Gil-Guirado, S.; Espín Sánchez, J. A.; Prieto, M. Del R. (2016). «Can we learn from the past? Four hundred years of changes in adaptation to floods and droughts. Measuring the vulnerability in two Hispanic cities», Climatic Change, vol. 139 (2), pp. 183-200.

GimÉnEz-Font, P. (2008). «La epidemia de malaria de 1783-1786: notas sobre la influencia de anomalías climáticas y cambios de usos del suelo en la salud humana», Investigaciones geográficas, vol. 46, pp. 141-157.

Grabuleda Teixidor, C. (2002). Salut pública i creixement urbà. Política i acció social en el sorgiment de la Barcelona contemporània. Barcelona: Universitat Pompeu Fabra. Institut Universitari d'Història Jaume Vicens Vives.

Grove, R. H. (1998). «Global Impact of the 1789-93 El Niño», Nature, vol. 393 (6683), pp. 318-319.

Jones, P. D.; Davies, T. D.; Lister, D. H.; Slonosky, V.; Jónsson, T.; Bärring, L. et al. (1999). «Monthly Mean Pressure Reconstructions for Europe for the 1780-1995 Period», International Journal of Climatology vol. 19, pp. 347-364.

JoRI, G. (2012). Salud pública e higiene urbana en España durante el siglo xVIII. Una perspectiva geográfica. Barcelona: Universidad de Barcelona.

López i Alemany, M. (1988a). «Contribució a la historia del paludisme a Amposta i Delta de l'Ebre. I: Dels orígens a 1900», Gimbernat: revista catalana d'bistòria de la medicina i de la ciència, vol. 10, pp. 179-194.

López i Alemany, M. (1988b). «Contribució a la historia del paludisme a Amposta i Delta de l'Ebre. II: De 1900 a 1936», Gimbernat: revista catalana d'bistòria de la medicina $i$ de la ciència, vol. 10, pp. 193-204.

MarTín Corrales, E. (2015). «La contaminación industrial en el litoral catalán durante el siglo XviI». En L. Cemeteri y X. Daumalin (dirs.). Pollutions industrielles et espaces méditerranéens xvıII-ххле siècle, Aix-en-Provence: Karthala, MMSH.

Masdevall i Terrades, J. (1786). Relación de las epidemias de calenturas pútridas y malignas que en estos últimos años se han padecido en el Principado de Cataluña y prin- 
cipalmente la que descubrió el año pasado de 1783 en la ciudad de Lérida, Llano de Urgél. Madrid: Imprenta Real.

Moreno Chacón, M. (2007). «El paisatge empordanès vist pels viatgers», Annals de l'Institut d'Estudis Empordanesos, vol. 2, pp. 525-534.

Pérez Moreda, V. (1980). Las crisis de mortalidad en la España interior, siglos XVI-XIX. Madrid: Siglo XXI.

Peset, J. L.; Peset, M. (1972). Muerte en España. Política y sociedad entre la peste y el cólera. Madrid: Seminarios y Ediciones.

Piquer, A. (1751). Tratado de las calenturas según la observación, y el mecanismo. Valencia: en la Imprenta de Joseph García.

Pometтi Benítez, K. (2014). «Tercianas y epizootias en la Barcelona de 1783-1786. Médicos, poder institucional y percepción social en la Barcelona de las postrimerías del siglo xviI», Pedralbes: revista d'bistòria moderna, vol. 34, pp. 433-444.

Pometтr Benítez, K. (2016). «Tertian Fevers in Catalonia in Late Eighteenth Centuries: The Case of Barcelona (1783-1786). A Methodological Proposal to Develop Studies over Endemic and Epidemic Malaria in Past Societies». En A. J. RodríGuez-Morales, (ed.). Current Topics in Malaria. Rijeka: IntechOpen, pp. 3-37.

Pometтi Benítez, K. (2018). «Barcelone, une ville entre deux épidémies à la fin du xvire siècle. Les répercussions des épidémies de fièvres tierces (1783-1786) sur la société». En I. SéGUY, M. GinNaIo y L. Buchet (dirs.). Les conditions sanitaires des populations du passé. Environnements, maladies, prophylaxies et politiques publiques. Antibes: Éditions APDCA, pp. 45-82.

PometTi Benítez, K. (2019a). Inestabilidad ambiental y salud pública en una ciudad mediterránea del Antiguo Régimen. Barcelona entre el paludismo y la fiebre amarilla (1780-1821). Aix-en-Provence: Aix-Marseille Université y Alicante: Universidad de Alicante.

PometTi Benítez, K. (2019b) «Clima, salud pública y sociedad: causas, gestión y efectos de la fiebre amarilla en la Barcelona de 1821», Cuadernos de Estudios del Siglo xvII, núm. 29, pp. 247-277.

Pometтi Benítez, K. (2020). «Fiebres, arroz e insalubridad: el caso del Ampurdán (1783-1787)», Revista de Historia Moderna. Anales de la Universidad de Alicante, núm. 38, pp. 221254.

Pons, F. (1790). Memoria práctica sobre las calenturas pútridas del Ampurdán. Barcelona: Imprenta de Eulalia Piferrer.

Prohom, M.; Barriendos, M.; Sánchez-Lorenzo, A. (2015). «Reconstruction and homogenization of the longest instrumental precipitation series in the Iberian Peninsula (Barcelona, 1786-2014)», International Journal of Climatology, vol. 36, p. 3072-3087. DOI: $10.1002 /$ joc. 4537.

Pujıula, J. (2008). «Notes per a una història de la sanitat pública a les comarques gironines», Revista de Girona, vol. 249, pp. 61-66.

Rico-Avello y Rico, C. (1953). Fiebre amarilla en España (epidemiología histórica). Madrid: Gráficas González. 
Riera Palmero, J. (1982). Estudios y documentos sobre arroz y paludismo en Valencia (s. xVIII). Valladolid: Ediciones de la Universidad de Valladolid, Secretariado de Publicaciones.

Riera Palmero, J. (1984). Fiebres y paludismo en la España Ilustrada: Félix Ibáñez y la epidemia de La Alcarria, 1784-1792. Valladolid: Universidad de Valladolid, Secretariado de Publicaciones.

Riera Palmero, J. (1992). "Guerra y epidemias (1793-1795) en Guipúzcoa y Navarra», Cuadernos de Sección. Ciencias Médicas, vol. 2, pp. 113-137.

Rodríguez Ocaña, E.; Ballester Añón, R.; Perdiguero, E.; Medina Doménech, R. M.; Molero Mesa, J. (2003). La acción médico-social contra el paludismo en la España metropolitana y colonial del siglo xx. Madrid: Consejo Superior de Investigaciones Científicas.

Rosen, G. (2015). A History of Public Health. Baltimore: Johns Hopkins University Press. SAEZ, J. M.; Marset Campos, P. (2000). «Teoría académica y práctica ciudadana en el paludismo. Las causas de las enfermedades endémicas en Murcia durante el siglo xviI desde la perspectiva de la administración local», Asclepio, vol. 52, núm. 1, pp. 167-183.

Salvá i Campillo, F. (1798). «Topografía del departamento destinado para las mujeres en el Real Hospicio de Barcelona, y epidemias observadas en él en 1787 y 1794, por el Doctor D. -, leídas por el [sic] mismo en las juntas de 24 de noviembre de 1787, y 30 del mismo mes de 1791». En Memorias de la Real Academia Médico Práctica de la ciudad de Barcelona: tomo primero, Madrid: Imprenta Real, pp. 408-450.

Sallares, R. (2002). Malaria and Rome: A History of Malaria in Ancient Italy, Oxford: Oxford University Press.

Sallares, R. (2005). «Pathocoenosis Ancient and Modern», History and Philosophy of the Life Sciences vol. 27 (2), p. 201-220.

Shrewsbury, J. F. D. (1970). A History of Bubonic Plague in the British Isles. Cambridge: Cambridge University Press.

Smith, K. R.; Woodward, A.; Campbell-Lendrum, D.; Chadee, D. D.; Honda, Y.; Liu, Q. et al. (2014). «Human health: impacts, adaptation, and co-benefits». En C. B. Field; V. R. Barros; D. J. Dokren; K. J. Mach; M. D. Mastrandrea; T. E. Bilir. et al. (eds.). Climate Change 2014: Impacts, Adaptation and Vulnerability. Part A: Global and Sectoral Aspects. Contribution of Working Group II to the Fifth Assessment Report of Intergovernmental Panel on Climate Change. Cambridge: Cambridge University Press, pp. 709-754.

Surroca i SEns, J. (1979). «El conreu de l'arròs a l'Empordà durant el segle xviI», Estudis d'Història Agrària, vol. 2, pp. 73-94.

Tejedor, E.; Luis, M. de; Barriendos, M.; Cuadrat, J. M.; Luterbacher, J.; Saz, M. Á. (2019). «Rogation ceremonies: a key to understanding past drought variability in northeastern Spain since 1650», Climate of the Past, vol. 15, pp. 1647-1664. DOI: 10.5194/cp-15-12019.

Tejedor, E.; Saz, M. Á.; Cuadrat, J. M.; Esper, J.; Luis, M. DE. (2017). «Temperature variability in the Iberian Range since 1602 inferred from tree-ring records», Climate of the Past, vol. 13, pp. 93-105. DOI: 10.5194/cp-13-93-2017. 
Trigo, R. M.; Vaquero, J. M.; Alcoforado, M. J.; Barriendos, M.; Taborda, J.; García-Herrera, R. et al. (2008). «Iberia in 1816, the year without a summer», International Journal of Climatology, vol. 29 (1), pp. 99-115. DOI: 10.1002/joc.1693.

Vargas Soler, J.; Morales Camacho, W. J.; Plata-Ortiz, S.; Macías Celis, A. C.; Nocua Alarcón, L. X.; Noguera-Sánchez, A. M. et al. (2020). «Sarampión en pediatría: el resurgir de una enfermedad prevenible por vacunación», Revista Mexicana de Pediatría, vol. 87 (1), pp. 30-37.

VILAR, P. (1966). Catalunya dins l'Espanya moderna: recerques sobre els fonaments econòmics de les estructures nacionals. Vol. 3. Barcelona: Edicions 62.

Wade, K. A.; Beye, S. A.; DiATtA, B. (2010). «Paludisme grave et fièvre jaune. Association souvent méconnue. Illustration à propos de deux observation», Médecine d'Afrique Noire, núm. 57, pp. 577-581.

White, S. (2011). The Climate of Rebellion in the Early Modern Ottoman Empire. Nueva York: Cambridge University Press.

Zarzoso, A. (2003). La pràctica mèdica a la Catalunya de segle xvIII. Barcelona: Universitat Pompeu Fabra.

Zulueta, J. De; Bruce-Chwatt, L. J. (1980). The rise and fall of malaria in Europe. A historico-epidemiological study. Oxford: Oxford University Press. 